\title{
The impact of vibrational Raman scattering of air on DOAS measurements of atmospheric trace gases
}

\author{
J. Lampel ${ }^{1, \text { a }}$, U. Frie $\beta^{1}$, and U. Platt ${ }^{1}$ \\ ${ }^{1}$ Institute of Environmental Physics, University of Heidelberg, Heidelberg, Germany \\ ${ }^{a}$ now at: Max Planck Institute for Chemistry, Mainz, Germany \\ Correspondence to: J. Lampel (johannes.lampel@iup.uni-heidelberg.de)
}

Received: 29 January 2015 - Published in Atmos. Meas. Tech. Discuss.: 31 March 2015

Revised: 26 August 2015 - Accepted: 27 August 2015 - Published: 17 September 2015

\begin{abstract}
In remote sensing applications, such as differential optical absorption spectroscopy (DOAS), atmospheric scattering processes need to be considered. After inelastic scattering on $\mathrm{N}_{2}$ and $\mathrm{O}_{2}$ molecules, the scattered photons occur as additional intensity at a different wavelength, effectively leading to "filling-in" of both solar Fraunhofer lines and absorptions of atmospheric constituents, if the inelastic scattering happens after the absorption.

Measured spectra in passive DOAS applications are typically corrected for rotational Raman scattering (RRS), also called Ring effect, which represents the main contribution to inelastic scattering. Inelastic scattering can also occur in liquid water, and its influence on DOAS measurements has been observed over clear ocean water. In contrast to that, vibrational Raman scattering (VRS) of $\mathrm{N}_{2}$ and $\mathrm{O}_{2}$ has often been thought to be negligible, but it also contributes.

Consequences of VRS are red-shifted Fraunhofer structures in scattered light spectra and filling-in of Fraunhofer lines, additional to RRS. At $393 \mathrm{~nm}$, the spectral shift is 25 and $40 \mathrm{~nm}$ for VRS of $\mathrm{O}_{2}$ and $\mathrm{N}_{2}$, respectively. We describe how to calculate VRS correction spectra according to the Ring spectrum.

We use the VRS correction spectra in the spectral range of $420-440 \mathrm{~nm}$ to determine the relative magnitude of the crosssections of VRS of $\mathrm{O}_{2}$ and $\mathrm{N}_{2}$ and RRS of air.

The effect of VRS is shown for the first time in spectral evaluations of Multi-Axis DOAS data from the SOPRAN M91 campaign and the MAD-CAT MAX-DOAS intercomparison campaign. The measurements yield in agreement with calculated scattering cross-sections that the observed VRS $\left(\mathrm{N}_{2}\right)$ cross-section at $393 \mathrm{~nm}$ amounts to $2.3 \pm 0.4 \%$ of the cross-section of RRS at $433 \mathrm{~nm}$ under tropospheric con-
\end{abstract}

ditions. The contribution of $\operatorname{VRS}\left(\mathrm{O}_{2}\right)$ is also found to be in agreement with calculated scattering cross-sections. It is concluded, that this phenomenon has to be included in the spectral evaluation of weak absorbers as it reduces the measurement error significantly and can cause apparent differential optical depth of up to $3 \times 10^{-4}$. Its influence on the spectral retrieval of IO, glyoxal, water vapour and $\mathrm{NO}_{2}$ in the blue wavelength range is evaluated for M91. For measurements with a large Ring signal a significant and systematic bias of $\mathrm{NO}_{2}$ dSCDs (differential slant column densities) up to $(-3.8 \pm 0.4) \times 10^{14} \mathrm{molec} \mathrm{cm}^{-2}$ is observed if this effect is not considered. The effect is typically negligible for DOAS fits with an RMS (root mean square) larger than $4 \times 10^{-4}$.

\section{Introduction}

The DOAS-technique (differential optical absorption spectroscopy) is widely used from different platforms to retrieve the abundance of tropospheric and stratospheric absorbers, such as ozone $\left(\mathrm{O}_{3}\right)$, nitrogen dioxide $\left(\mathrm{NO}_{2}\right)$ and many others. Observation geometries include zenith-sky, direct-sun and off-axis measurement of sunlight scattered in the atmosphere (e.g. Platt and Stutz, 2008). The Multi-Axis (MAX)DOAS principle allows for the reaching of high sensitivity to tropospheric absorbers, such as, e.g. $\mathrm{NO}_{2}$, iodine monoxide $(\mathrm{IO})$, bromine monoxide $(\mathrm{BrO})$, water vapour $\left(\mathrm{H}_{2} \mathrm{O}\right)$, the oxygen dimer $\left(\mathrm{O}_{4}\right)$, glyoxal $(\mathrm{CHOCHO})$ and formaldehyde (HCHO) (e.g. Peters et al., 2012; Großmann et al., 2013; Frieß et al., 2011; Wagner et al., 2013; Mahajan et al., 2014; Pinardi et al., 2013). 
Solar absorption lines (Fraunhofer lines) have an effect on the evaluation of scattered sunlight spectra, since inelastic scattering processes in the atmosphere lead to an effective "filling-in" of these absorption lines. The reduction of the optical depths (OD) of Fraunhofer lines is known as the Ring effect (Shefov, 1959; Grainger and Ring, 1962). While originally several mechanisms for the Ring effect were proposed (Burrows et al., 1996, and references therein) there is a consensus in recent literature that most properties of the Ring effect can be described by rotational Raman scattering (Solomon et al., 1987; Fish and Jones, 1995; Joiner and Bhartia, 1995; Joiner et al., 1995; Burrows et al., 1996; Vountas et al., 1998).

However, for large amounts of filling-in of Fraunhofer lines, i.e. a strong Ring signal, Schönhardt et al. (2008) reported problems with the spectral retrieval of IO from satellite measurements at wavelengths above $431 \mathrm{~nm}$. Unexplained residual optical depths were observed, indicating an effect that was not considered in the spectral analysis. We propose that this effect is at least partly due to vibrational Raman scattering (VRS) in the atmosphere. This spectral region (i.e. $430-440 \mathrm{~nm}$ ) is actually the location of the strong Ca lines of the Fraunhofer spectrum, red-shifted by the excitation energy of the first vibrational eigenstate of $\mathrm{N}_{2}$.

This is a first indication that this effect might indeed be relevant for measurements of atmospheric absorbers. Additionally, Coburn et al. (2011) reported that despite co-adding of measurement spectra, the size of the residual spectral structures from MAX-DOAS observations in the blue wavelength range did not reduce as expected from photon statistics. They suggested that an insufficiently modelled Ring spectrum or a missing contribution such as vibrational Raman scattering is causing this difference. In spectral retrievals of trace gases encompassing the wavelength range between 430 and $440 \mathrm{~nm}$, this effect is currently not explicitly considered.

Figure 1 shows the cross-section of rotational and vibrational Raman scattering for forward scattering of a monochromatic light beam at $393 \mathrm{~nm}$ (the position of the solar calcium-II K-absorption line). While the pure rotational Raman lines of $\mathrm{N}_{2}$ or $\mathrm{O}_{2}$ appear in the vicinity of the wavelength region of $393 \mathrm{~nm}$, the rotational-vibrational Raman (Stokes) lines of $\mathrm{N}_{2}$ and $\mathrm{O}_{2}$ are considerably red-shifted according to their different vibrational constants. VRS of $\mathrm{O}_{2}$ leads to a red-shift of the calcium-II K-absorption line of $25 \mathrm{~nm}$, VRS of $\mathrm{N}_{2}$ to $40 \mathrm{~nm}$. Note that anti-Stokes lines are very weak under atmospheric conditions, since only a small fraction of the $\mathrm{N}_{2}$ and $\mathrm{O}_{2}$ molecules is vibrationally excited. The rotational and vibrational constants are listed in Table 1. Thus, strong Fraunhofer lines can give rise to VRS - "ghost" absorption lines in other parts of the spectrum.

Platt et al. (1997) mentioned that VRS of air can lead to apparent ODs of up to $0.3 \%$ in zenith sky measurements. Vountas et al. (1998) estimated the effect of single vibrational Raman scattering to the filling-in of Fraunhofer lines to be less than $0.3 \%$ and did not discuss it further. Haug (1996)

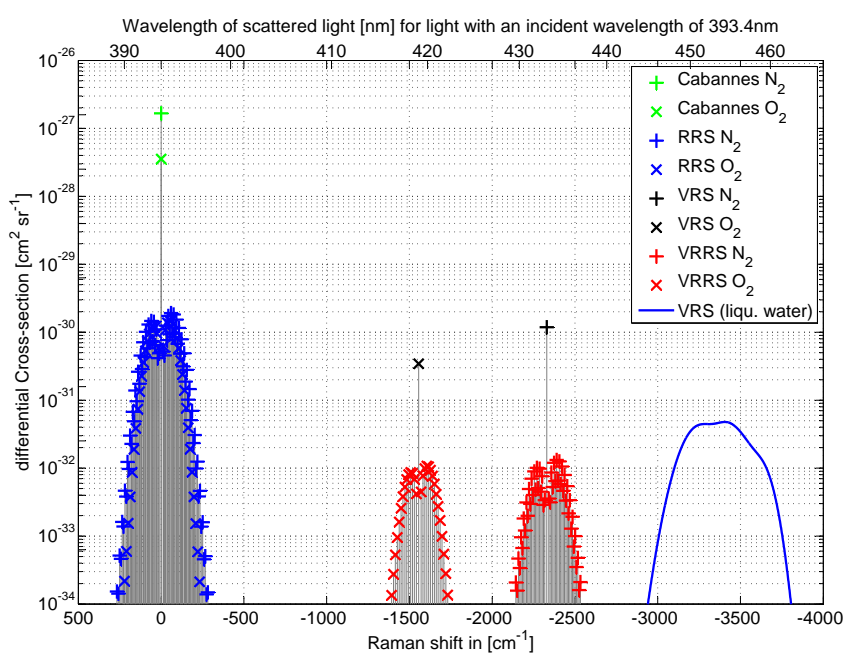

Figure 1. Cross-section of Cabannes line, rotational (RRS rotational Raman scattering), vibrational (VRS) and rotationalvibrational Raman scattering (VRRS) for a wavelength of $393 \mathrm{~nm}$ scaled with 0.8 for $\mathrm{N}_{2}$ and 0.2 for $\mathrm{O}_{2}$ to reflect their atmospheric concentrations (see also Table 9). The cross-sections were calculated according to Eq. (13) at a scattering angle of $\Theta=180^{\circ}$. As a comparison the Raman response of liquid water according to Haltrin and Kattawar (1993) is also shown in the plot, scaled arbitrarily.

Table 1. The rotational constant $B_{0}$ and the vibrational constant $\widetilde{v}$ for ground state $\mathrm{N}_{2}$ and $\mathrm{O}_{2}$ according to Irikura (2007). For excited vibrational states $v>0$ the rotational constant is modified: $B_{v}=$ $B_{0}-v \cdot \alpha_{e}$. These constants are used in Eq. (1) to calculate the energy of the molecule $E(v, J)$.

\begin{tabular}{llll}
\hline Molecule & $\begin{array}{l}B_{0} \\
{\left[\mathrm{~cm}^{-1}\right]}\end{array}$ & $\begin{array}{l}\widetilde{v} \\
{\left[\mathrm{~cm}^{-1}\right]}\end{array}$ & $\begin{array}{l}\alpha_{e} \\
{\left[\mathrm{~cm}^{-1}\right]}\end{array}$ \\
\hline $\mathrm{N}_{2}$ & 1.98958 & 2329.9 & 0.01732 \\
$\mathrm{O}_{2}$ & 1.43765 & 1556.3 & 0.01593 \\
\hline
\end{tabular}

and Platt and Stutz (2008) estimated the filling-in to be 0.02$0.22 \%$, which results in $2-14 \%$ of the filling-in due to rotational Raman scattering. However, none of these publications showed experimental evidence from DOAS measurements to support their estimates.

In addition, also water vapour exhibits narrow vibrational Raman transitions, with a frequency shift of around $3654 \mathrm{~cm}^{-1}$ (Penney and Lapp, 1976; Murphy, 1978) and with a cross-section of $8( \pm 20 \%) \times 10^{-30} \mathrm{~cm}^{2} \mathrm{sr}^{-1}$ (Rizi et al., 2004) about 5-10 times as strong as the vibrational Raman scattering cross-section of the $\Delta v=1$ transition of $\mathrm{N}_{2}$ (depending on the scattering angle). This effectively leads to a wavelength shift of the Ca-Fraunhofer lines to about $460 \mathrm{~nm}$, but this should usually not be observable in current DOAS measurements since the expected OD would be below $5 \times 10^{-5}$ for a typical tropospheric water vapour column density of $5 \times 10^{23} \mathrm{molec} \mathrm{cm}^{-2}$ along a light path of $10 \mathrm{~km}$. 
Inelastic scattering of air and water vapour is however used in LIDAR applications (Weitkamp, 2005).

In the atmosphere, not only monochromatic light is scattered by air molecules, but rather a continuous incident light spectrum from the Sun. The solar spectrum is highly structured by Fraunhofer lines. These spectral structures are redshifted by VRS and will result in so-called "Fraunhofer ghosts" in another spectral interval. If this additional intensity is not explicitly corrected for, it can lead to errors in the retrieved trace gas concentrations. Intensities of elastically and inelastically scattered sunlight are shown in Fig. 2, together with a constant offset (e.g. caused by instrumental stray light) and vibrational Raman scattering in liquid water (Vountas et al., 2003; Dinter et al., 2015).

Inelastically scattered light appears as an additional intensity in measured spectra. When the scattering medium does not exhibit narrow excitation states, this can lead to a "blurred" remapping of the solar spectrum. This is the case for some liquids and solids. A blurred remapping of the solar spectrum is also observed for RRS and vibrational rotational Raman scattering (VRRS) of $\mathrm{N}_{2}$ and $\mathrm{O}_{2}$, since the respective cross-subsections consist of several lines separated by only a few $\mathrm{cm}^{-1}$, which are not separated in typical DOAS measurements. Vibrational Raman scattering in liquid water has been reported by Vasilkov et al. (2002) and Vountas et al. (2003). Similar to ice, liquid water has a broad Raman spectrum (Raman shift of $\approx 3300 \mathrm{~cm}^{-1}$ with a FWHM of $\approx 500 \mathrm{~cm}^{-1}$, which converts to a shift of $\approx 61 \mathrm{~nm}$ at $\lambda=400 \mathrm{~nm}$ and a FWHM of $\approx 11 \mathrm{~nm}$ at $\lambda^{\prime}=461 \mathrm{~nm}$, according to Haltrin and Kattawar, 1993) and thus essentially creates an intensity offset in measurement spectra. Therefore, the VRS (liq. $\mathrm{H}_{2} \mathrm{O}$ ) correction spectrum for this effect is similar to the intensity offset polynomial often used in DOAS evaluations to compensate for intensity offsets caused by instrumental stray-light, but has a broad-band $(10 \mathrm{~nm})$ modulation of its amplitude (Richter et al., 2011; Peters et al., 2014). This broad Raman response is shown in Fig. 1 and leads to inelastically scattered light with a smooth spectrum as shown in Fig. 2. As shown by Peters et al. (2014), this can have a significant impact on MAX-DOAS measurements of $\mathrm{NO}_{2}$, especially when looking downwards into clear water.

The liquid water Raman cross-section also shows a frequency shift of $\approx 1650$ and $\approx 2100 \mathrm{~cm}^{-1}$, but the relative cross-section is together about 5 times smaller (Schmidt and Miki, 2007).

The individual lines of the Raman cross-section of RRS and VRRS cannot be resolved by typical DOAS instruments. Therefore the scattered light intensity due to RRS and VRRS is also a smooth function of wavelength, compared to the original Sun spectrum.

In contrast to that, the vibrational Raman spectra of $\mathrm{N}_{2}$ and $\mathrm{O}_{2}$ contain individual and narrow peaks, therefore resulting in narrow-band contributions to the total measured OD. If vibrational Raman ghosts of strong Fraunhofer lines happen to occur in a spectral region which is relevant for the spectral retrieval, these can also affect the spectral retrieval of trace gases.

The additional intensity offset, which is included in several settings for DOAS evaluations of stray-light spectra is typically meant to compensate for a constant contribution to the measured intensity due to instrumental stray-light. As it turns out, this correction term also compensates for a large fraction of the contribution of vibrational Raman scattering in the atmosphere, especially involving transitions due to VRRS.

\section{Quantitative description of rotational and vibrational Raman scattering by $\mathrm{N}_{2}$ and $\mathrm{O}_{2}$}

Inelastic scattering results in a change of the energy of the scattered photon and of the scattering molecule. The energy of the molecule is characterized by the vibrational $(v)$ and rotational $(J)$ quantum numbers and given by

$$
\begin{aligned}
E(\nu, J) & =E_{\mathrm{rot}}+E_{\mathrm{vib}} \\
& =h c B J(J+1)+h c \widetilde{v}\left(v+\frac{1}{2}\right),
\end{aligned}
$$

assuming no coupling between rotation and vibration, which is a reasonable approximation for typical spectral resolutions used in DOAS applications $(0.5-1.0 \mathrm{~nm}) . B$ is the rotational constant in wavenumbers and $\widetilde{v}$ is the wavenumber in $\mathrm{cm}^{-1}$ corresponding to the energy difference between the vibrational states (compare Table 1; see Table 4 for a list of variables). To avoid confusion with the vibrational quantum number $v$, the vibrational constant of a molecule in units of wavenumbers is denoted $\widetilde{v}$. Allowed transitions are denoted by $\Delta J=0, \pm 2$ resulting in the $Q(\Delta J=0), O(\Delta J=-2)$ and $S$ branches $(\Delta J=2)$ and $\Delta v=1$ for vibrational transitions. Due to the temperatures in the Earth's atmosphere $T$, only the ground vibrational state is occupied significantly, thus leading only to Stokes transitions of the vibrational states. ( $E_{\mathrm{vib}} / k T \approx 11$ and 8 for $\mathrm{N}_{2}$ and $\mathrm{O}_{2}$, respectively.)

The scattered power density $I_{v, J \rightarrow v^{\prime}, J^{\prime}}$ in $\mathrm{W} \mathrm{m}^{-2}$ scattered into the full solid angle $4 \pi$ involving a transition $(v, J \rightarrow$ $v^{\prime}, J^{\prime}$ ) is given, e.g. by Long (2002):

$$
I_{\nu, J \rightarrow \nu^{\prime}, J^{\prime}}=I_{I} \sigma_{\nu, J \rightarrow v^{\prime}, J^{\prime}} L N g_{J}(2 J+1) \frac{1}{Z} e^{-E(\nu, J) / k T},
$$

where $I_{I}$ is the incident power density, $N$ the number density of molecules in the scattering volume, $L$ the length of the scattering volume (i.e. its extent in the direction of the line of sight of the instrument) and $g_{J}$ is the statistical weight factor of the initial rotational state due to the nuclear spin (see Table 2). The sum over states $\mathrm{Z}$ is given below. $J$ and $v$ describe the initial state and $J^{\prime}$ and $v^{\prime}$ describe the final state. The factor $(2 J+1)$ accounts for the degeneracy due to the magnetic quantum numbers while $\exp (-E(v, J) / k T)$ accounts for the population of the initial state of the molecule at temperature $T$. The absolute cross-section in Eq. (2) is given by 

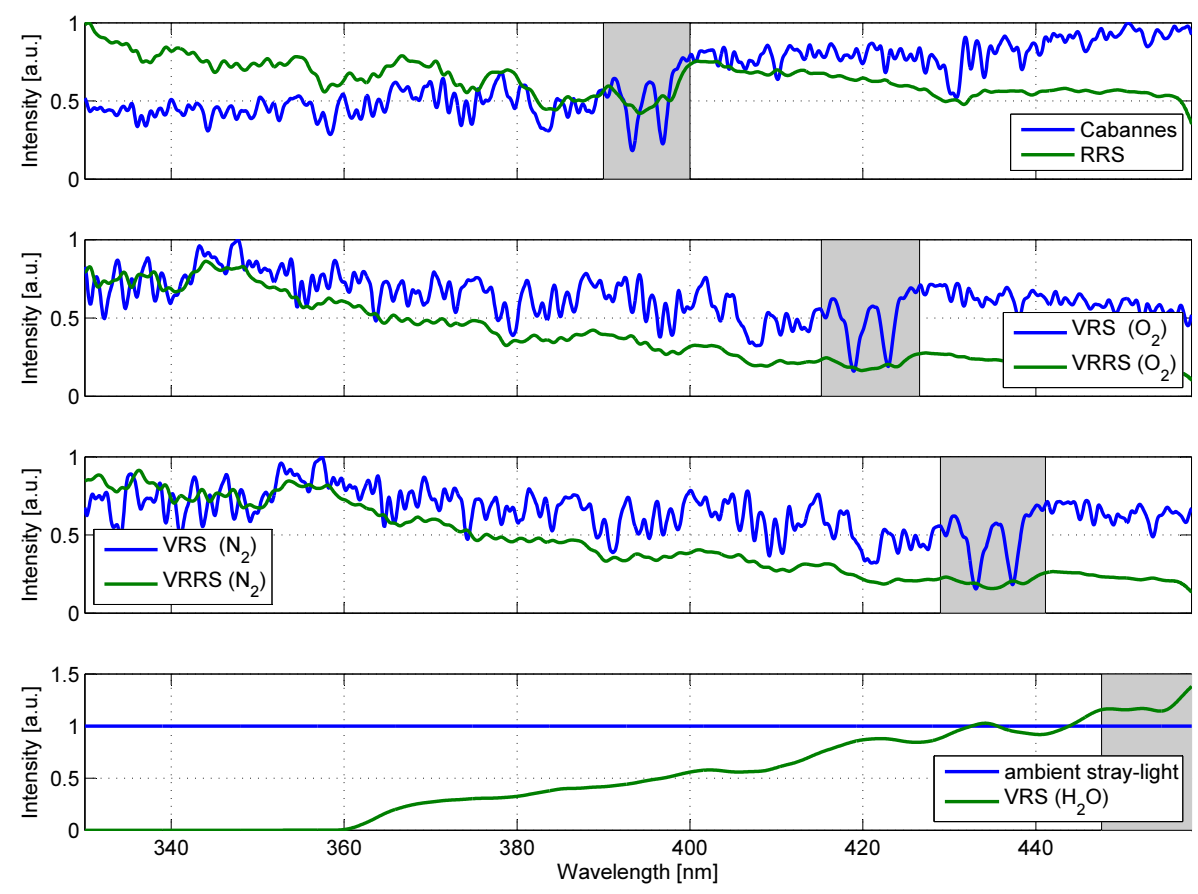

Figure 2. Calculated intensities (in arbitrary units) for purely Rayleigh scattered light (Cabannes), rotational Raman scattered light (RRS), vibrational Raman scattered light (VRS), and combined scattering (VRRS) due to $\mathrm{N}_{2}, \mathrm{O}_{2}$ and liquid water as well as assumed instrumental stray-light as a function of wavelength at a spectral resolution of $0.5 \mathrm{~nm}$. The apparent optical depths $I_{\text {add }} / I_{0}$ according to Eq. (18) are shown in Fig. 3. The relative magnitudes for each of the effects are arbitrarily scaled. Note the red-shift in the VRS $\left(\mathrm{O}_{2}\right)$ and VRS( $\left.\mathrm{N}_{2}\right)$ spectrum compared to the solar atlas; the Ca-II lines and their respective ghost lines for inelastic scattering on $\mathrm{N}_{2}, \mathrm{O}_{2}$ and liquid water are marked gray. For the absolute magnitudes of the cross-sections compare Table 9.

Table 2. The statistical weight factor $g_{J}$ due to nuclear spin $(I)$ statistics for odd and even shell angular momentum $J$ of the respective $\mathrm{N}_{2}$ or $\mathrm{O}_{2}$ molecule.

\begin{tabular}{llll}
\hline $\begin{array}{l}\text { Molecule } \\
J\end{array}$ & $I$ & $\begin{array}{l}g_{J} \\
\text { odd }\end{array}$ & $\begin{array}{l}g_{J} \\
\text { even }\end{array}$ \\
\hline $\mathrm{N}_{2}$ & 1 & 3 & 6 \\
$\mathrm{O}_{2}$ & 0 & 0 & 1 \\
\hline
\end{tabular}

$\sigma_{v, J \rightarrow v^{\prime}, J^{\prime}}$ which can be obtained via the integration of the differential cross-section $\frac{\mathrm{d} \sigma(\Theta)_{v, J \rightarrow v^{\prime}, J^{\prime}}}{\mathrm{d} \Omega}$ (see Eq. 3) over the entire solid angle (note that the term differential refers here to the solid angle).

The differential cross-section for an incident light beam with the wavenumber $\widetilde{v}_{\text {in }}$ in $\mathrm{cm}^{-1}$ can be written as

$$
\begin{array}{r}
\frac{\mathrm{d} \sigma(\Theta)_{v, J \rightarrow v^{\prime}, J^{\prime}}}{\mathrm{d} \Omega}=8 \pi^{4}\left(\widetilde{v}_{\text {in }}+\widetilde{v}_{\nu, J \rightarrow v^{\prime}, J^{\prime}}\right)^{4} \frac{1}{2 J+1} \\
\sum_{M, M^{\prime}} \sum_{i j}\left[\alpha_{i j}^{2}\right]_{\left(v, J, M \rightarrow v^{\prime}, J^{\prime}, M^{\prime}\right)} f_{i j}(\Theta),
\end{array}
$$

where $\alpha_{i j}$ are the entries of the polarizability tensor as given by Long (2002). These can be spatially averaged over the magnetic quantum numbers $M, M^{\prime}$ since the molecules' orientations in space are arbitrary, which results in the spatially averaged squares of the polarization tensor entries, $\overline{\alpha_{i j}^{2}}$, see Table 5, which is given by

$$
\overline{\left[\alpha_{i j}^{2}\right]_{\left(v, J \rightarrow v^{\prime}, J^{\prime}\right)}}=\frac{1}{2 J+1} \sum_{M, M^{\prime}}\left[\alpha_{i j}^{2}\right]_{\left(v, J, M \rightarrow v^{\prime}, J^{\prime}, M^{\prime}\right)}
$$

The invariants of this tensor are the average polarizability $a$ and the anisotropy $\gamma$ and $a^{\prime}$ and $\gamma^{\prime}$, their derivatives with respect to nuclear coordinates for vibrational-rotational transitions, respectively. Their contributions to the cross-section corresponding to different transitions are listed in Table 5. The wavelength dependence of $a, a^{\prime}, \gamma$ and $\gamma^{\prime}$ is small (for $\gamma$ less than $5 \%$ variation for wavelengths from 400 to $500 \mathrm{~nm}$, see Bates, 1984, for example) and is therefore neglected here.

The Placzek-Teller coefficients $b_{J, J^{\prime}}$ used in Table 5 can be found at Penney et al. (1974):

$$
\begin{aligned}
& b_{J \rightarrow J}=\frac{J(J+1)}{(2 J-1)(2 J+3)} \\
& b_{J \rightarrow J+2}=\frac{3(J+1)(J+2)}{2(2 J+1)(2 J+3)} \\
& b_{J \rightarrow J-2}=\frac{3 J(J-1)}{2(2 J+1)(2 J-1)} .
\end{aligned}
$$


Table 3. Averaged polarizability $a, a^{\prime}$ and anisotropy $\gamma, \gamma^{\prime}$ according to Weitkamp (2005) and references therein for incident wavelengths between 400 and $500 \mathrm{~nm}$. The resulting differential cross-sections $\mathrm{d} \sigma / \mathrm{d} \Omega$ are listed in Table 9.

\begin{tabular}{lllll}
\hline Molecule & $a^{2}$ & $\gamma^{2}$ & $a^{\prime 2}$ & $\gamma^{\prime 2}$ \\
& $\mathrm{~m}^{6} /\left(4 \pi \epsilon_{0}\right)^{2}$ & $\mathrm{~m}^{6} /\left(4 \pi \epsilon_{0}\right)^{2}$ & $\mathrm{~m}^{4} \mathrm{~kg}^{-1} /\left(4 \pi \epsilon_{0}\right)^{2}$ & $\mathrm{~m}^{4} \mathrm{~kg}^{-1} /\left(4 \pi \epsilon_{0}\right)^{2}$ \\
\hline $\mathrm{N}_{2}$ & $3.17 \times 10^{-60}$ & $0.52 \times 10^{-60}$ & $2.62 \times 10^{-14}$ & $4.23 \times 10^{-14}$ \\
$\mathrm{O}_{2}$ & $2.66 \times 10^{-60}$ & $1.26 \times 10^{-60}$ & $1.63 \times 10^{-14}$ & $6.46 \times 10^{-14}$ \\
\hline
\end{tabular}

Table 4. Variables used in equations

\begin{tabular}{ll}
\hline$\widetilde{v}_{i n}$ & Wavenumber of incident photon \\
$\lambda$ & Wavelength \\
$\nu$ & Quantum number of vibrational eigenstate \\
$J$ & Quantum number of rotational eigenstate \\
$\widetilde{v}$ & Vibrational constant, in wavenumbers (Table 1) \\
$\mathrm{B}$ & Rotational constant, in wavenumbers (Table 1) \\
$E(\nu, J)$ & Energy of molecule in state $(v, J)$ (Eq. 1) \\
$E_{\mathrm{rot}}(v, J)$ & Rotational energy \\
$E_{\mathrm{vib}}(\nu, J)$ & Vibrational energy \\
$\mathrm{M}$ & Magnetic quantum number \\
$\Omega$ & Solid angle \\
$\sigma$ & Cross-section \\
$\Theta$ & Scattering angle \\
$\alpha, \alpha^{\prime}$ & Polarizability and its derivative (Table 3) \\
$\gamma, \gamma^{\prime}$ & Anisotropy and its derivative (Table 3) \\
$I_{I}$ & Incident power density \\
$b_{J \rightarrow J^{\prime}}$ & Placzek-Teller coefficient (Eq. 5) \\
$g_{J}$ & Statistical weight factor (Table 2) \\
$T$ & Temperature \\
$L$ & Length of scattering volume \\
$N$ & Number density of scattering molecules \\
$Z$ & Partitioning function (section 2.1) \\
$I_{0}$ & Measured Fraunhofer reference spectrum \\
$I^{*}$ & Solar atlas (Chance and Kurucz, 2010) \\
$\tau$ & Optical depth \\
$H\left(\lambda, \lambda^{\prime}\right)$ & Instrument slit function \\
\hline &
\end{tabular}

\subsection{Sum over states}

The sum over states (or partitioning function) $Z=Z_{\mathrm{rot}} Z_{\mathrm{vib}}$ is given by the product of the rotational state sum $Z_{\text {rot }}$ and the vibrational state sum $Z_{\mathrm{vib}}$ :

$$
\begin{aligned}
& Z_{\mathrm{rot}}=\sum_{J}^{\infty} g_{J}(2 J+1) e^{-E_{\mathrm{rot}}(J) / k T} \\
& Z_{\mathrm{vib}}=\sum_{\nu}^{\infty} e^{-E_{\mathrm{vib}}(v) / k T}
\end{aligned}
$$

$Z_{\text {vib }}$ can be calculated explicitly using a geometric series:

$$
Z_{\mathrm{vib}}=\frac{e^{-\frac{h \widetilde{v}}{2 k T}}}{1-e^{-\frac{h c \widetilde{v}}{k T}}} .
$$

\subsection{Phase function}

The geometric factors $f_{i j}(\Theta)$ in Eq. (3) are determined by the relative orientations of the incident light polarization, the polarizability tensor and the direction of observation, given by the scattering angle $\Theta$. Using Table 5 the non-normalized phase function $p^{\prime}(\Theta)$ for each of the scattering processes can be calculated. $p^{\prime}(\Theta)^{\mathrm{VRS}}$ depends thus also on the ratio of $b^{\prime 2}=\frac{\gamma^{\prime 2}}{a^{\prime 2}}$ and shows more dominant scattering into the forward and backward direction and differs for $\mathrm{N}_{2}$ and $\mathrm{O}_{2}$, compare Table 3. The phase function of VRS is similar to the Rayleigh phase function.

$$
\begin{aligned}
& p^{\prime}(\Theta)^{\mathrm{RRS}}=p^{\prime}(\Theta)^{\mathrm{VRRS}}=13+\cos ^{2}(\Theta) \\
& p^{\prime}(\Theta)^{\mathrm{VRS}}=\left(1+\frac{7}{45} b^{\prime 2}\right)+\left(1+\frac{3}{45} b^{\prime 2}\right) \cdot \cos ^{2}(\Theta)
\end{aligned}
$$

\subsection{Total cross-section}

From the general expression for the total cross-section

$\sigma^{\text {total }}=\sum_{\nu, J} \sigma_{\nu, J \rightarrow v^{\prime}, J^{\prime}} \frac{1}{Z} g_{J}(2 J+1) e^{-E(v, J) / k T}$

the total cross-section of the $Q$ branch of the vibrational transition can now be calculated (e.g. Schrötter and Klöckner, 1979) by summing over all possible transitions of the $Q$ branch $(\Delta J=0 ; \Delta v=1)$ and averaging the respective phase functions over the full solid angle:

$$
\begin{aligned}
\sigma^{Q, \text { total }}= & \frac{128 \pi^{5}\left(\widetilde{v}_{\text {in }}+\widetilde{v}\right)^{4}}{9\left(1-e^{-h c \widetilde{v} / k T}\right)} \\
& {\left[3 a^{\prime 2}+\frac{2}{3} \gamma^{\prime 2} S_{\Delta J=0}\right] \frac{h}{8 c \pi^{2} \widetilde{v}} }
\end{aligned}
$$

using

$$
S_{\Delta J=0}=\sum_{J} \frac{1}{Z_{\mathrm{rot}}} g_{J}(2 J+1) b_{J, J} e^{-E_{\mathrm{rot}}(J) / k T} .
$$

$\sigma^{Q \text {,total }}$ depends only slightly on the temperature, since also $S_{\triangle J=0}$ varies by less than $1 \%$ between $T=230 \mathrm{~K}$ and $T=298 \mathrm{~K}$ and the term $1-e^{-h c \widetilde{v} / k T}$ less than $10^{-4}$. The numerical values for the resulting overall cross-section are given in Table 9. The important information for passive DOAS applications is the $\left(\widetilde{v}_{\text {in }}+\widetilde{v}\right)^{4}$-dependency from 
Table 5. Spatial averaged polarization tensor according to Long (2002) and corresponding phase functions $f(\Theta)$.

\begin{tabular}{llll}
\hline & Transition & $\overline{\left[\alpha_{i i}^{2}\right]_{\left(v, J \rightarrow v^{\prime}, J^{\prime}\right)}}$ & $\overline{\left[\alpha_{i j}^{2}\right]_{\left(v, J \rightarrow \nu^{\prime}, J^{\prime}\right)}}$ \\
\hline Cabannes & $\Delta v=0, \Delta J=0$ & $a^{2}+\frac{4}{45} b_{J \rightarrow J} \gamma^{2}$ & $\frac{1}{15} b_{J \rightarrow J} \gamma^{2}$ \\
RRS & $\Delta v=0, \Delta J= \pm 2$ & $\frac{4}{45} b_{J \rightarrow J \pm 2} \gamma^{2}$ & $\frac{1}{15} b_{J \rightarrow J \pm 2} \gamma^{2}$ \\
VRS & $\Delta v=1, \Delta J=0$ & $\left(a^{\prime 2}+\frac{4}{45} b_{J \rightarrow J} \gamma^{\prime 2}\right) \frac{h}{8 c \pi^{2} \widetilde{v}}$ & $\left(\frac{1}{15} b_{J \rightarrow J} \gamma^{\prime 2}\right) \frac{h}{8 c \pi^{2} \widetilde{v}}$ \\
VRRS & $\Delta v=1, \Delta J= \pm 2$ & $\left(\frac{4}{45} b_{J \rightarrow J \pm 2} \gamma^{\prime 2}\right) \frac{h}{8 c \pi^{2} \widetilde{v}}$ & $\left(\frac{1}{15} b_{J \rightarrow J \pm 2} \gamma^{\prime 2}\right) \frac{h}{8 c \pi^{2} \widetilde{v}}$ \\
\hline$f(\Theta)$ & & $1+\cos ^{2}(\Theta)$ & $3-\cos ^{2}(\Theta)$ \\
\hline
\end{tabular}

Eq. (14), together with the spectral shift $\widetilde{v}$ (Table 1) itself. This information already allows the calculation of correction spectra in a first approximation. The remaining calculations are necessary to obtain the absolute magnitude of the effect. The resulting apparent optical densities are shown in Fig. 3. Equation (14) was used to calculate the spectra provided in the Supplement. Figure 1 was calculated using Eq. (13).

\section{Experimental method}

The DOAS method (Platt and Stutz, 2008) uses the attenuation of light from a light source by absorbers within the light path according to Lambert-Beer's law. The optical depth (OD)

$\tau(\lambda)=-\ln \frac{I(\lambda)}{I_{0}(\lambda)}$

from two spectra $I(\lambda)$ and $I_{0}(\lambda)$ is used to determine the column density of different absorbers in the respective wavelength range. Each of the absorbers is identified by its specific absorption structures. To remove broad-band extinction from particles and molecules, the OD is subdivided into a narrow-band (differential) and a broad-band part, $\tau=$ $\tau_{\mathrm{B}}+\tau_{\mathrm{d}} \cdot \tau_{\mathrm{d}}$ can then be expressed by a sum of the differential parts of possible absorbers with their differential absorption cross-sections $\sigma_{\mathrm{d}, i}$, assuming that these are constant with pressure and temperature. $c_{i}(l)$ are the respective concentrations along the light path $L$.

$\tau_{\mathrm{d}}=\sum_{i} \sigma_{\mathrm{d}, i} \int_{0}^{L} c_{i}(l) \mathrm{d} l$

The method of Multi-Axis DOAS (MAX-DOAS) measurements was first described by Hönninger and Platt (2002) and uses scattered sunlight at different elevation angles, which have each a different sensitivity for absorptions in different heights in the atmosphere.

The SCD is defined by the integral over the concentration $c_{i}$ along the light path $L$ and is hence given in the unit molec $\mathrm{cm}^{-2}$. Differential slant column densities $\mathrm{dSCD}_{i}$ can be calculated from MAX-DOAS measurements for each fitted trace gas: a Fraunhofer reference spectrum $I_{0}$ is chosen and $d S C D(\alpha)=\mathrm{SCD}_{(\alpha)}-\mathrm{SCD}_{\text {ref }}$ is obtained from the DOAS fit of the OD for each elevation angle $\alpha$.

\subsection{Instrumentation}

The effect of VRS of $\mathrm{N}_{2} / \mathrm{O}_{2}$ is shown for two measurement campaigns, using two different spectrometers and telescopes at different locations. The M91 campaign data set shows low $\mathrm{NO}_{2}$ concentrations at a high spectral resolution using an Acton spectrometer. The measurements took place on the $\mathrm{Pa}$ cific. To exclude possible interferences from liquid water absorption and VRS of liquid water, the MAD-CAT data set was analysed: this data set was recorded during a MAXDOAS intercomparison campaign in Mainz. However, this data set was recorded with a compact spectrometer at lower spectral resolution and $\mathrm{NO}_{2}$ and glyoxal concentrations were significantly larger.

\subsubsection{M91}

The MAX-DOAS measurements used here were recorded during research cruise M91 of the German research vessel Meteor in the Peruvian Upwelling (Bange, 2013). The cruise was part of the Surface Ocean Processes in the Anthropocene (SOPRAN) project as part of SOLAS (Surface Ocean - Lower Atmosphere Study). The ship left Callao $\left(12^{\circ} 2^{\prime} 30^{\prime \prime} \mathrm{S}, 77^{\circ} 8^{\prime} 36^{\prime \prime} \mathrm{W}\right)$, the harbour of Lima, on 1 December 2012. It then sailed north until $5^{\circ} \mathrm{S}$ and continued south along transects perpendicular to the coastline until $18^{\circ} \mathrm{S}$ and arrived again in Lima on 26 December 2012. A cruise track is shown in Fig. 4.

The MAX-DOAS instrument consisted of three main parts: a telescope unit mounted on top of the air chemistry lab on RV Meteor headed towards port side in a height of approximately $28 \mathrm{~m}$, a temperature stabilized Acton spectrometer located inside the lab and a PC to control the devices. The same setup was used by Großmann et al. (2013).

The telescope unit has an inclinometer to correct the ship's roll angle for elevation angles close to the horizon. Its output is directly fed into the motor controller and can correct the elevation angle at an accuracy of $\approx 0.5^{\circ}$ while the ship's roll 

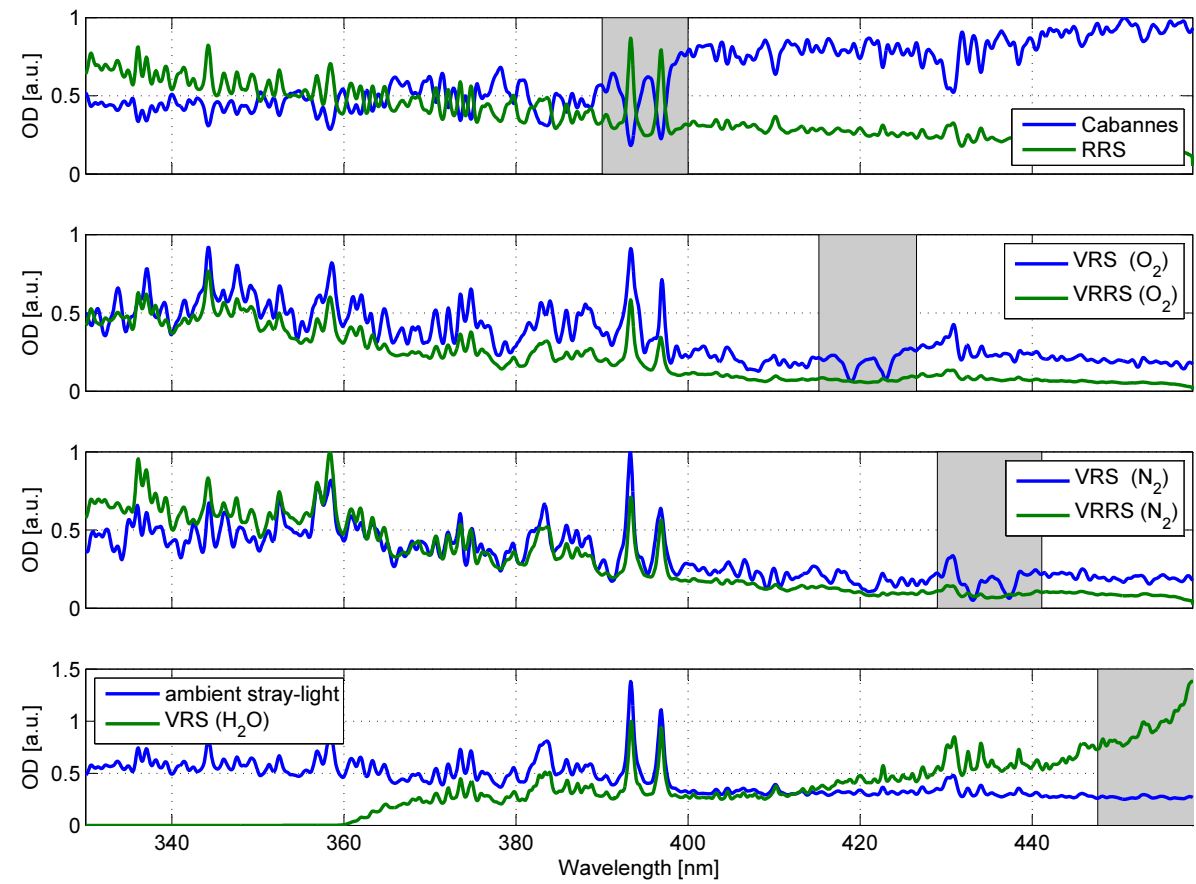

Figure 3. The apparent optical depths according to Eq. (18) related to the additional intensities in Fig. 2.

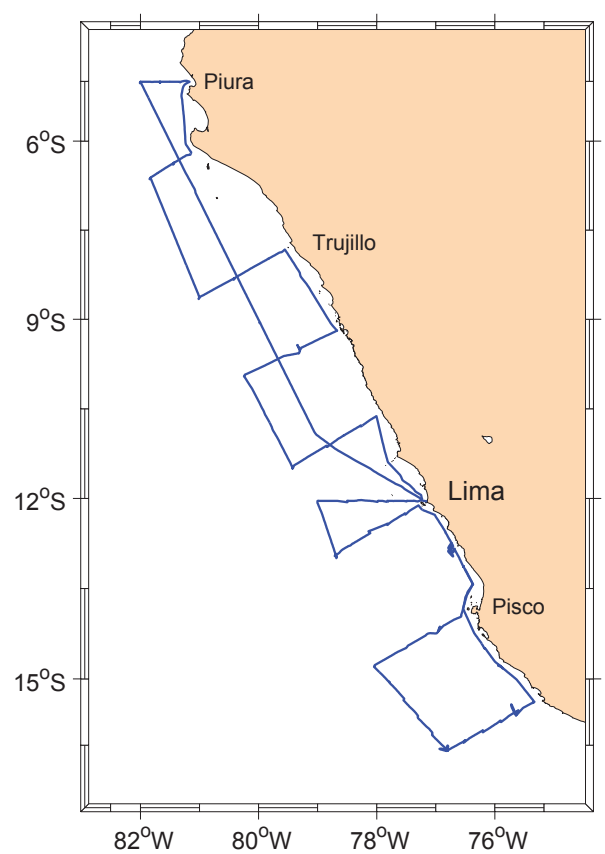

Figure 4. Track of cruise Meteor M91. From Lima, the ship first sailed north until about Piura and then continued south along transects from the open ocean to the coastal upwelling or vice versa until $18^{\circ} \mathrm{S}$, from where it returned to Lima.

is less than $8^{\circ}$, which was the case most of the time. The light from the telescope is focused via a lens onto a mode mixing fibre which was then connected to 37 circularly arranged fi- bres of $100 \mu \mathrm{m}$ diameter. These fibres are then again used as the entrance slit of the spectrometer. To avoid the influence of direct sunlight reflected in the entrance of the telescope, a $5 \mathrm{~cm}$ long baffle was attached.

The spectrometer used was an Acton 300i that was temperature stabilized at $44^{\circ} \mathrm{C}$ with an Andor CCD camera DU $440-\mathrm{BU}$. The camera was used in imaging mode recording $256 \times 2048$ pixel. The detector of the camera was cooled to $-30{ }^{\circ} \mathrm{C}$ to reduce the dark-current signal. This setup covered a wavelength range of $324 \mathrm{~nm}-467 \mathrm{~nm}$. The full-width-halfmaximum resolution was $0.45 \mathrm{~nm}$ or 6.5 pixel.

During daylight, spectra were recorded for $1 \mathrm{~min}$ each at 8 elevation angles of $90^{\circ}$ (zenith), 40, 20, 10, 6, 4, 2, $1^{\circ}$, respectively, as long as solar zenith angles (SZAs) were $\leq 85^{\circ}$. During twilight $\left(85^{\circ} \leq \mathrm{SZA} \leq 105^{\circ}\right)$, spectra were alternatingly recorded at 90 and $2^{\circ}$ elevation. The exposure time was adjusted to have spectra at a typical saturation of $50 \%$. At night $\left(\mathrm{SZA} \geq 110^{\circ}\right)$ dark current and offset spectra were recorded automatically. Mercury discharge lamp spectra to obtain the instrument slit function $H\left(\lambda, \lambda^{\prime}\right)$ were recorded manually. No significant change of the instrument slit function shape was observed during the campaign. DOAS fits using one fixed Fraunhofer reference show that the variation in wavelength calibration during 1 day was less than $0.01 \mathrm{~nm}$.

The FWHM (full width half maximum) of the mercury emission lines at $404.7,407.8$ and $435.8 \mathrm{~nm}$ differed by $2 \%$ assuming a Gaussian shape. A fit of the measured spectrum to a solar atlas using a Gaussian instrument function with a linearly wavelength dependent width for the main fit interval from 420 to $440 \mathrm{~nm}$ also showed in agreement 
a variation of the width of the slit function of less than $2 \%$. A difference of $2 \%$ error in slit function width would result for an absorption corresponding to a $\mathrm{NO}_{2} \mathrm{dSCD}$ of $5 \times 10^{16}$ molec $^{-2}$ (differential OD at instrument resolution: $1.6 \times 10^{-2}$ ) in a residual structure of $1 \times 10^{-4}$ peak to peak. This $\mathrm{NO}_{2} \mathrm{dSCD}$ was exceeded only once during the whole cruise in the port of Callao, typical values during the cruise were $(2 \pm 5) \times 10^{14} \mathrm{molec}^{-2}$ at a telescope elevation angle of $3^{\circ}$, compare also Fig. 9.

\subsubsection{MAD-CAT}

The Multi Axis DOAS - Comparison campaign for Aerosols and Trace gases (MAD-CAT) in Mainz/Germany took place on the roof of the Max Planck Institute for Chemistry (MPIC). The measurement site is located close to the city of Mainz and surrounded by Frankfurt as well as several smaller cities. 11 research groups participated with the MAX-DOAS instruments. ${ }^{1}$ (see also e.g. Ortega et al., 2014).

One of the instruments was the Heidelberg Envimes MAX-DOAS. It is based on an Avantes ultra-low stray-light AvaSpec-ULS2048x64 spectrometer $(f=75 \mathrm{~mm})$ using a back-thinned Hamamatsu S11071-1106 detector. The spectrometer is temperature stabilized $\left(\Delta T<0.02^{\circ} \mathrm{C}\right)$. It covered a spectral range of $294-458 \mathrm{~nm}$ at a FWHM spectral resolution of $\approx 0.6 \mathrm{~nm}$ or $\approx 7$ pixel. The spectral stability was typically better than $\pm 3 \mathrm{pm}$ per day and better than $\pm 5 \mathrm{pm}$ for the duration of the measurements from 6 June 2013 until 31 July 2013. Mercury discharge lamp spectra to obtain the instrument slit function $H\left(\lambda, \lambda^{\prime}\right)$ were recorded manually. No significant change of the instrument slit function shape was observed during the campaign. The 1-D-telescope unit measures its elevation angle constantly using a MEMS acceleration sensor, and corrects the elevation angle, when it deviates from the nominal elevation angle. It has a vertical/horizontal field of view (FOV) of $0.2 / 0.8^{\circ}$.

During daylight, spectra were recorded for $1 \mathrm{~min}$ each at 11 elevation angles of $90^{\circ}$ (zenith), 30, 15, 10, 8, 6- $1^{\circ}$ respectively, as long as solar zenith angles (SZA) were $\leq 87^{\circ}$. Until a SZA of $100^{\circ}$ zenith sky spectra were recorded at $90^{\circ}$ telescope elevation. The exposure time was adjusted to have spectra at a typical saturation of $50 \%$.

The FWHM of mercury emission lines at 404.7, 407.8 and $435.8 \mathrm{~nm}$ differed by $2.5 \%$ assuming a Gaussian shape. A fit of the measured spectrum to a solar atlas using a Gaussian instrument function with a linearly wavelength dependent width for the main fit interval from 420 to $440 \mathrm{~nm}$ also showed in agreement a variation of the width of the slit function of less than $2.5 \%$.

\subsection{Spectral retrieval}

The aim of the spectral retrieval was to identify the contribution of inelastic scattering due to $\operatorname{VRS}\left(\mathrm{N}_{2} / \mathrm{O}_{2}\right)$ to mea-

\footnotetext{
${ }^{1}$ http://joseba.mpch-mainz.mpg.de/mad_cat.htm
}

sured intensities in MAX-DOAS measurements. The most pronounced signal is expected between 430 and $440 \mathrm{~nm}$, as the calcium Fraunhofer line ghosts due to $\operatorname{VRS}\left(\mathrm{N}_{2}\right)$ are expected to be found here. As a number of absorbers show absorption structures in this spectral range, these had to be included in the fit or their detection limits had to be determined. An overview over the respective settings in shown in Table 8.

The recorded scattered sunlight spectra were analyzed for absorptions using the software package DOASIS (Kraus, 2006). A measured Fraunhofer reference spectrum (FRS) $I_{0}$ from the current elevation sequence at an elevation angle of $90^{\circ}$ for MAD-CAT was chosen. For M91 $40^{\circ}$ spectra were used to avoid direct sunlight into the telescope in the southern part of the cruise track. The measured OD $\tau_{\mathrm{Obs}}$ was then calculated for each spectrum $I$ (Eq. 16).

In order to reduce noise of both data sets, several elevation sequences were co-added. When adding 16 elevation sequences for M91 (corresponding to $2 \mathrm{~h}$ measurement time), a mean RMS (root mean square) of the residual of $7.5 \times 10^{-5}$ is observed. Example fits are shown in Fig. 5 for both campaigns. Adding more than 16 elevation sequences is typically not possible due to instrumental instabilities and changing atmospheric conditions and radiative transfer. For residual spectra dominated by photon shot noise, the RMS depends on the integrated intensity I as $\sqrt{I}$ according to Poisson statistics. When increasing the number of co-added spectra, the residual will be eventually dominated by systematic structures. This behaviour can be visualized in a so-called Allan plot (plotting RMS vs. intensity on a log-log scale) and was used to find a compromise between time resolution and low RMS. This led to summing 16 elevation sequences for the M91 data set. For the MAD-CAT data set more elevation angles were recorded, and therefore only eight elevation sequences were co-added to obtain a similar time resolution of $1.5 \mathrm{~h}$.

The pixel to wavelength mapping for the recorded spectra was performed by using mercury emission lines. The correctness of the pixel to wavelength mapping was tested by convoluting a high-resolution sunlight spectrum by Chance and Kurucz (2010) and comparing it to a measured spectrum.

The broad-band contributions to the observed optical depth were compensated by a polynomial fitted together with the trace gases. The (rotational) Ring spectrum was taken from DOASIS where it is calculated according to Bussemer (1993) for each Fraunhofer reference spectrum, agreeing with the expression given in Eq. (2), without vibrational transitions. A second Ring spectrum, the original one scaled by $\lambda^{4} / \lambda_{0}^{4}-1$ to account for radiative transfer effects discussed in Wagner et al. (2009) was also included in the fit and was clearly detected in the measured OD.

The second Ring spectrum compensates for additional Ring spectrum structures which appear with a changing colour index within one elevation sequence, for example, due to particle scattering at lower elevation angles. The first Ring spectrum is calculated according to Eqs. (2) and (18). How- 

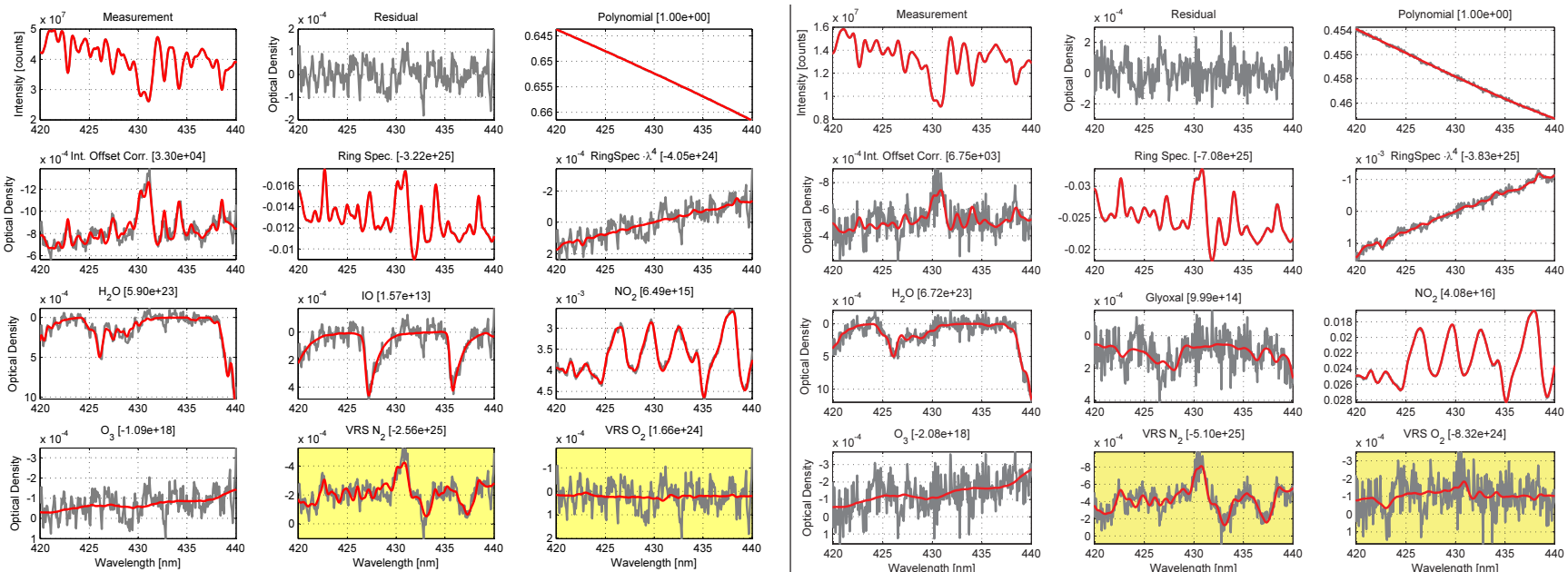

$\mathrm{NO}_{2}[408 \mathrm{e}+16$

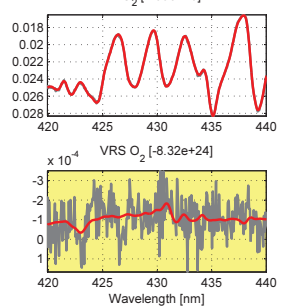

Figure 5. (left) Fit showing the detection of structures from vibrational Raman scattering of $\mathrm{N}_{2}$ for a spectrum recorded during M91. The main peak at $430 \mathrm{~nm}$ originates from the reciprocal of a Fraunhofer structure at this wavelength from the Taylor expansion of the optical thickness. It vanishes when orthogonalizing the spectrum with the stray light compensation spectrum $1 / I_{0}$. The two minima to at 432 and $436 \mathrm{~nm}$ are the red-shifted calcium Fraunhofer lines. The grey lines are measured quantities, the red line is the modelled OD. The spectrum was recorded on 15 December 2012, starting at 17:38 UTC, at $12^{\circ} 33^{\prime} \mathrm{S}, 76^{\circ} 50^{\prime} \mathrm{W}$ at a SZA of $14^{\circ}$ and a relative solar azimuth angle (SAA) of $132^{\circ}$. The FRS spectrum was recorded at $40^{\circ}$ elevation. 16 elevation sequences were co-added, resulting in a time resolution of $2 \mathrm{~h}$ and a total exposure time of $16 \mathrm{~min}$ per co-added spectrum. The Fraunhofer reference spectrum was omitted for clarity. Column densities are given in molec $\mathrm{cm}^{-2}$. The unit of the measurement spectrum and the intensity offset correction is given in counts. (right) Detection of structures from vibrational Raman scattering on $\mathrm{N}_{2}$ in data from MAD-CAT. The spectrum was recorded on 15 June 2013, starting at 13:32 UTC, in Mainz, Germany at a SZA of $27^{\circ}$ and a relative SAA of $122^{\circ}$. The FRS spectrum was recorded at $90^{\circ}$ elevation. Eight elevation sequences were co-added, resulting in a time resolution of $1.5 \mathrm{~h}$ and a total exposure time of $8 \mathrm{~min}$.

ever, if in Eq. (18) the colour index of I' changes (e.g. due to scattering on particles), this translates directly to the Ring correction spectrum. The second Ring spectrum compensates for this effect.

The spectrum was calculated by multiplication of the original Ring spectrum by $\left(\lambda^{4} / \lambda_{0}^{4}-1\right)$. By construction, this Ring correction spectrum vanishes at the wavelength $\lambda_{0}$, which is used then as the wavelength of the RRS signal to be compared to the VRS signal. It is almost orthogonal to the Ring spectrum in the interval from 420 to $440 \mathrm{~nm}$ : by comparison with an explicitly orthogonalized second Ring spectrum (within the complete fit interval) the change in Ring dSCD was found to be less than $1 \times 10^{24}$ molec $\mathrm{cm}^{-2}$ for both data sets used. This is less than $2 \%$ of the range of observed Ring signals, as shown in Fig. (6).

The cross-sections listed in Table 6 were used after being convolved with the instrument slit function. The instrument slit function was measured as the response of the spectrometer to the mercury emission line at $404.7 \mathrm{~nm}$. It was assumed to be constant, in Sect. 3.1.1 an error estimate is given for this assumption for the case of strong $\mathrm{NO}_{2}$ absorption. A parameterization by a Gaussian function with a wavelength dependent width would have also introduced uncertainties, since the slit function shape of both spectrometers is not exactly of Gaussian shape.
It was not necessary to incorporate tropospheric ozone absorption cross-sections in the fit, since the expected OD due to stratospheric ozone is $\tau \leq 1 \times 10^{-4}$. However, the resulting stratospheric light-path change during morning and evening made it necessary to include an ozone cross-section measured at $223 \mathrm{~K}$ by Serdyuchenko et al. (2014). The zeroth order intensity offset correction was realized by including an inverse reference spectrum in the DOAS fit according to Eq. (18).

For water vapour absorptions based on HITEMP (Rothman et al., 2013), the relative sizes of the absorption bands in the fit interval were adjusted according to Lampel et al. (2015). This correction was not crucial for the detection of VRS, but yields reasonable water vapour dSCDs even for the weak water vapour absorption band at $426 \mathrm{~nm}$.

While for the Ring spectrum neither shift nor squeeze was allowed, the remaining cross-sections' shift and squeeze parameter were linked together and determined by fitting the measurement spectrum against the Kitt Peak Flux Atlas 2010 by Chance and Kurucz (2010). No significant differences were found when determining the shift and squeeze of all cross-sections together using the Levenberg Marquard implementation of the DOAS-fit within DOASIS as shown in Table 7. 
Table 6. Cross-sections used for the spectral (DOAS) retrieval. All shift and squeeze parameters of the cross-sections were linked, those of Ring and reference spectrum were linked separately. The retrieval interval settings for each used trace gas are given in Table 8.

\begin{tabular}{lll}
\hline Absorber & Source & dSCD for $I_{0}$ correction \\
\hline $\mathrm{NO}_{2} 294 \mathrm{~K}$ & Vandaele et al. (1998) & $1 \times 10^{15} \mathrm{molec} \mathrm{cm}^{-2}$ \\
$\mathrm{O}_{3} 223 \mathrm{~K}$ & Serdyuchenko et al. (2014) & $1 \times 10^{18} \mathrm{molec} \mathrm{cm}^{-2}$ \\
$\mathrm{IO}$ & Spietz et al. (2005) & $1 \times 10^{13} \mathrm{molec} \mathrm{cm}^{-2}$ \\
$\mathrm{H}_{2} \mathrm{O}$ & Rothman et al. (2013) with corrections Lampel et al. (2015) & $3 \times 10^{23} \mathrm{molec} \mathrm{cm}^{-2}$ \\
\hline Glyoxal & Volkamer et al. (2005) & $5 \times 10^{14} \mathrm{molec} \mathrm{cm}^{-2}$ \\
$\mathrm{O}_{4} 293 \mathrm{~K}$ & Thalman and Volkamer (2013) & $3 \times 10^{43} \mathrm{molec}^{-2} \mathrm{~cm}^{-5}$ \\
Liquid water & Pope and Fry (1997) & \\
VRS(liqu. water) & based on Haltrin and Kattawar (1993) & \\
\hline Ring & by DOASIS (Kraus, 2006) and Bussemer (1993) \\
Ring $\cdot \lambda^{4}$ & Wagner et al. (2009) & used for I correction and \\
\hline Solar atlas & Chance and Kurucz (2010) & VRS correction spectra \\
\hline
\end{tabular}

Table 7. Impact on the ratio of $\operatorname{VRS}\left(\mathrm{N}_{2}\right)$ and RRS depending on different fit settings for the spectral retrieval, given in $\%$ relative to the standard settings, where the shift of the literature cross-section was determined from a fit using a convolved solar atlas. The mean RMS for all settings did not vary by more than $5 \%$ around the mean RMS of $7.5 \times 10^{-5}$ for the standard setting.

\begin{tabular}{lllll}
\hline Setting & Shift & Squeeze & Ring $\times \lambda^{4}$ & $\begin{array}{l}\text { Impact } \\
\text { VRS(N }\end{array}$ \\
\hline Standard & sol. atlas & none & yes & - \\
1 & sol. atlas & none & no & $+3 \%$ \\
2 & free & free & yes & $+3 \%$ \\
3 & free & free & no & $+5 \%$ \\
4 & free & none & yes & $-10 \%$ \\
4 & free & none & no & $-14 \%$ \\
\hline
\end{tabular}

\subsubsection{M91}

The effect of vibrational Raman scattering in liquid water on the spectral retrieval of IO has been discussed in greater detail in Großmann et al. (2013) using a spectrum based on Vountas et al. (2003). This correction spectrum was not used here, since it was not clearly identified for positive elevation angles. If there was any contribution, it is most likely compensated to a large extend by the intensity offset correction within this relatively small wavelength interval as discussed in Richter et al. (2011). Even for a larger fit window (432$460 \mathrm{~nm}$, including a differential structure of liquid water at $451 \mathrm{~nm}$, see also Table 8) a contribution of VRS of liquid water and/or liquid water absorption could not be identified for spectra recorded at positive elevation angles. The maximum ratio of liquid water absorption and its typical fit error of $0.07 \mathrm{~m}$ was 2.9 . A mean value of $-0.08 \mathrm{~m}$ and a standard deviation of $0.20 \mathrm{~m}$ was found. OMI satellite measurements shown in Peters et al. (2014) showed up to $8 \mathrm{~m}$ water column absorption in the remote Pacific, but less than $0.4 \mathrm{~m}$ in the Peruvian upwelling region. This could be explained by high turbidity due to high bio-productivity in this region (see e.g. Capone and Hutchins, 2013). The contribution of VRS was not significantly correlated with the liquid water absorption $\left(R^{2}=0.03, p=0.1\right)$ and was not found in measurement data above a detection limit defined as 4 times the DOAS fit error.

Glyoxal shows absorption structures in the spectral range which is can be affected by VRS. It could therefore interfere in the spectral retrieval of the $\operatorname{VRS}\left(\mathrm{N}_{2} / \mathrm{O}_{2}\right)$ signal. Despite previously reported significant absorption of glyoxal in the eastern Pacific region by Sinreich et al. (2010), no absorption of glyoxal during the M91 cruise was found to exceed our detection limit of $2 \sigma=5 \times 10^{14}$ molec cm $^{-2}$ at low elevation angles of $1-3^{\circ}$ in the wavelength interval from 432 to $460 \mathrm{~nm}$ using the settings from Table 8 . This is in agreement with other observations listed in Mahajan et al. (2014). Sensitivity studies for glyoxal were performed using different $\mathrm{O}_{4}$ literature cross-sections published by Hermans et al. (1999); Greenblatt et al. (1990) and Thalman and Volkamer (2013). The average observed glyoxal dSCD was found between (1 and $2 \pm 3) \times 10^{14} \mathrm{molec} \mathrm{cm}^{-2}$, resulting in surface concentrations of $(10 \pm 15) \mathrm{ppt}$. In the wavelength interval used here from 420 to $440 \mathrm{~nm}$ this upper limits corresponds to an OD of glyoxal of less than $10^{-4}$. Consequently, the glyoxal crosssection was not included in the final DOAS analysis of the M91 data.

\subsubsection{MAD-CAT}

On the contrary, glyoxal was found in significant amounts during the MAD-CAT campaign. Glyoxal dSCDs at low elevation angles of up to $4.5 \times 10^{15}$ molec $\mathrm{cm}^{-2}$ were found in both fit intervals listed in Table 8 . 
Table 8. Retrieval wavelength intervals for the MAX-DOAS measurements from M91 and MAD-CAT using the literature absorption crosssections listed in Table 6.

\begin{tabular}{|c|c|c|c|c|c|}
\hline Settings for: & & $\operatorname{VRS}\left(\mathrm{N}_{2} / \mathrm{O}_{2}\right)$ & $\operatorname{VRS}\left(\mathrm{N}_{2} / \mathrm{O}_{2}\right)$ & $\begin{array}{c}\text { Glyoxal } \\
\text { Liquid water } \\
\text { VRS(liq. water) }\end{array}$ & Glyoxal \\
\hline Campaign: & & M91 & MAD-CAT & M91 & MAD-CAT \\
\hline Wavelength interval & & $420-440 \mathrm{~nm}$ & $420-440 \mathrm{~nm}$ & $432-460 \mathrm{~nm}$ & $432-458 \mathrm{~nm}$ \\
\hline $\mathrm{O}_{3}$ & $223 \mathrm{~K}$ & $\mathrm{x}$ & $\mathrm{x}$ & $\mathrm{x}$ & $\mathrm{x}$ \\
\hline $\mathrm{NO}_{2}$ & $293 \mathrm{~K}$ & $\mathrm{x}$ & $\mathrm{x}$ & $\mathrm{x}$ & $\mathrm{x}$ \\
\hline $\mathrm{O}_{4}$ & & & & $\mathrm{x}$ & $\mathrm{x}$ \\
\hline $\mathrm{H}_{2} \mathrm{O}$ & $298 \mathrm{~K}$ & $\mathrm{x}$ & $\mathrm{x}$ & $\mathrm{x}$ & $\mathrm{x}$ \\
\hline $\mathrm{IO}$ & & $\mathrm{x}$ & & $\mathrm{x}$ & \\
\hline Glyoxal & & & $\mathrm{x}$ & $\mathrm{x}$ & $\mathrm{x}$ \\
\hline Liquid water & & & & $\mathrm{x}$ & \\
\hline Ring spectrum & & $\mathrm{x}$ & $\mathrm{x}$ & $\mathrm{x}$ & $\mathrm{x}$ \\
\hline Ring spectrum $\cdot \lambda^{4}$ & & $\mathrm{x}$ & $\mathrm{x}$ & $\mathrm{x}$ & $\mathrm{x}$ \\
\hline VRS N 2 & & $\mathrm{x}$ & $\mathrm{x}$ & $\mathrm{x}$ & $\mathrm{x}$ \\
\hline $\mathrm{VRS} \mathrm{O}_{2}$ & & $\mathrm{x}$ & $\mathrm{x}$ & $\mathrm{x}$ & $\mathrm{x}$ \\
\hline VRS (liq. water) & & & & $\mathrm{x}$ & \\
\hline Polynomial degree & & 3 & 3 & 3 & 3 \\
\hline Int. offset polynomial degree & & 0 & 0 & 1 & 1 \\
\hline
\end{tabular}

Therefore the glyoxal cross-section had to be included in the final DOAS analysis of the MAD-CAT data.

However, IO could not be identified in this data set exceeding the detection limit of $2 \sigma=6 \times 10^{12}$ molec $\mathrm{cm}^{-2}$ at low elevation angles of $1-3^{\circ}$ in the wavelength interval from 418 to $438 \mathrm{~nm}$. The site of the campaign was inland, and enhanced $\mathrm{NO}_{2}$ concentrations were observed, which could have led to a fast reaction of $\mathrm{IO}$ with $\mathrm{NO}_{2}$, if any $\mathrm{IO}$ was initially present. The IO cross-section was therefore not included in the final DOAS analysis of the MAD-CAT measurements.

\subsubsection{VRS correction spectra}

According to Eq. (2) the intensity correction spectra for vibrational Raman scattering can be calculated, either based on a solar atlas (Chance and Kurucz, 2010) or on measured spectra of scattered sunlight. Both approximations hold, since the filling-in due to RRS is of the order of $2 \%$ and the inelastic scattering occurs somewhere within the atmosphere. VRS of $\mathrm{N}_{2} / \mathrm{O}_{2}$ contributes by about $2 \%$ of the RRS, the overall OD for the VRS correction spectrum is then $0.04 \%$. Therefore, a relative uncertainty of $2 \%$ of the VRS correction spectrum is typically negligible. However, if this accuracy is needed, radiative transfer modelling similar to existing studies on rotational Raman scattering (e.g. Rozanov and Vountas (2014)) is indeed necessary. When calculating the VRS correction spectrum from measurement spectra, wavelength changes in the instrument slit function and the quantum efficiency of the spectrometer need to be considered.

Scattering can add an intensity $K(\lambda)=\sum_{i} K_{i}(\lambda)$ to the measured intensity $I(\lambda)=I^{\prime}(\lambda)+K(\lambda)$. This will lead to an apparent absorption structure in the optical depth $\tau_{\mathrm{Obs}}(\lambda)$. $I$ is the measured intensity of the measurement spectrum, $I^{\prime}(\lambda)$ would be the intensity without the contribution of additional intensities $K_{i}(\lambda)$ and $I_{0}(\lambda)$ is the intensity of the Fraunhofer reference spectrum.

$$
\begin{aligned}
\tau_{\mathrm{Obs}}= & -\ln \left(\frac{I^{\prime}+\sum_{i} K_{i}}{I_{0}}\right) \approx \tau-\sum_{i} \frac{K_{i}}{I^{\prime}} \\
& \approx \tau-\sum_{i} \frac{K_{i}}{I_{0}}
\end{aligned}
$$

The additional measured intensities $K_{i}(\lambda)$ can be caused by RRS of $\mathrm{N}_{2}, \mathrm{O}_{2}$, VRS of $\mathrm{N}_{2}, \mathrm{O}_{2}$, water vapour or liquid water, but also by instrumental stray light leading to an (approximately) wavelength-independent intensity offset. Equation (18) is linear in $K_{i}(\lambda)$, therefore the different components can be fitted separately to the observed OD. $K_{\mathrm{VRS} \mathrm{N}_{2}}(\lambda)$ can be calculated by shifting a sunlight spectrum in frequency by $\widetilde{v}_{\mathrm{N}_{2}}$ and scaling by $\left(\widetilde{v}_{\text {in }}+\widetilde{v}_{\mathrm{N}_{2}}\right)^{4}$ and $K_{\text {VRS_O }}(\lambda)$ respectively (see Eq. 14). Under the assumption that the rotational constant of $\mathrm{N}_{2}$ and $\mathrm{O}_{2}$ is independent of the vibrational state (which is the case within $1.2 \%$ for the $v=0,1$ states for $\mathrm{O}_{2}$ and $\mathrm{N}_{2}$, see Table 1), the intensity caused by vibrational-rotational transitions was calculated also using DOASIS, after a shift of the wavelength axis according to the vibrational constants for $\mathrm{N}_{2}$ and $\mathrm{O}_{2}$. The calculation within DOASIS agrees with Eq. (13) for the rotational transitions.

The optical depth $\tau_{\text {VRS }}(\lambda)$ can be fitted to correct for the additional intensity caused by vibrational Raman scattering, in this case based on solar atlas $I^{*}$, from which also $K_{\mathrm{VRS}}(\lambda)$ 
was calculated ( $\otimes$ denotes the convolution operation here):

$\tau_{\mathrm{VRS}}=\frac{K_{\mathrm{VRS}} \otimes H}{I^{*} \otimes H}$.

When using a solar atlas, effects caused by the (typically unknown) quantum efficiency of the measuring spectrometer cancel out and do not introduce additional residual structures. As mentioned above, also measurement spectra could be used to calculate the correction spectrum. Here a solar atlas was used.

\section{Results}

The following two subsections describe two ways how to detect the VRS signature in MAX-DOAS measurements: in the first approach the correction spectra are calculated and directly fitted to the measured optical depths. The obtained fit coefficients are compared to the Ring signal to determine the relative sizes of the cross-sections. In the second approach the residuals from a standard fit are analyzed systematically using a multi-linear regression. This offers the possibility to average over the residual spectra of a complete campaign to minimize photon shot noise. It allows for the detection of the contribution of VRS of $\mathrm{N}_{2}$ as well as of $\mathrm{O}_{2}$ from spectral data. It furthermore yields estimates on the impact of VRS on the calculated dSCDs of other absorbers.

\subsection{Detection of the VRS signal}

The VRS correction spectra $\tau_{\text {VRS }}$ for $\mathrm{N}_{2}$ and $\mathrm{O}_{2}$ were calculated according to Eq. (19) from a solar atlas and then separately included in the spectral evaluation of the measurements in the spectral range of $420-440 \mathrm{~nm}$. This wavelength range has been chosen to avoid the main water vapour absorptions at 416 and $442 \mathrm{~nm}$ and to include the main Fraunhofer ghosts at 433 and $436 \mathrm{~nm}$ due to $\operatorname{VRS}\left(\mathrm{N}_{2}\right)$.

The results for M91 of the spectral analysis of 16 co-added elevation sequences ( $2 \mathrm{~h}$ time resolution) were filtered: only spectra with a low fit residual with a root mean square (RMS) of less than $1.5 \times 10^{-4}$ were used. This ensures that spectra during twilight and/or high $\mathrm{NO}_{2}$ concentrations, which can increase the overall residual of the fit, are not included in the further analysis.

The results for MAD-CAT of the spectral analysis of eight co-added elevation sequences ( $1.5 \mathrm{~h}$ time resolution) were filtered additionally to use only measurements with a $\mathrm{NO}_{2}$ $\mathrm{dSCD}$ of less than $7 \times 10^{16}$ molec $\mathrm{cm}^{-2}$ to avoid an influence of large $\mathrm{NO}_{2}$ absorptions on the detection of the weak VRS signal. This filter removed $28 \%$ of all measurements.

The absolute cross-section of VRS is small and the mean free path for VRS and RRS is significantly larger than the scale height of the atmosphere (See cross-sections in Table 9). The light paths in Eq. (2) are thus the same for both effects and cancel out. This then allows for the estimation of the size of the cross-section of VRS relative to the crosssection of RRS.

A comparison of the VRS and RRS signal is shown for each campaign in Fig. 6. For M91, a clear correlation of the contribution of rotational Raman scattering with the contribution from vibrational Raman scattering on $\mathrm{N}_{2}$ is observed $\left(R^{2}=0.8\right)$; on is also observed for MAD-CAT $\left(R^{2}=0.7\right)$. The contribution from $\mathrm{O}_{2}$ is also positively correlated with the Raman signal, but the slope is nearly zero within the measurement error $\left(R^{2}=0.1\right)$. For MAD-CAT this correlation is stronger $\left(R^{2}=0.17\right)$. For both campaigns, the contribution from rotational-vibrational inelastic scattering was not identified in measurement spectra. The relative magnitude of the cross-sections of RRS and VRS is calculated from the slope of the linear fits shown in Fig. 6. In Table 9 the results are listed and compared to calculations.

The effective contribution to the measured intensity was estimated by using the Fraunhofer line at $\lambda=430 \mathrm{~nm}$ : The intensity caused by each of the processes, RRS, VRS $\mathrm{N}_{2}$ and VRS $\mathrm{O}_{2}$ at this wavelength will create a maximum in the respective pseudo cross-section $I_{\operatorname{Raman}}(\lambda) / I_{0}(\lambda)$, which then allows for the estimation of constant intensity offsets due to these processes.

A perfect correlation of both effects is not expected, because the phase function for VRS and RRS differ, as shown in Sect. 2.2.

\subsection{An alternative way of VRS signal detection}

Alternatively, the optical depth due to VRS can be extracted from residual spectra of a DOAS fit using only the crosssections listed in Table 6 and correction spectra calculated according to Eq. (18). A schematic of both approaches is shown in Fig. 7 and is here applied to the M91 data set. From the underlying properties of VRS described in Sect. 2 a linear relationship between the observed RRS and VRS signal is expected. This relationship is found for actual MAXDOAS measurements as shown in Fig. 6. Parameters which can modify this relation are discussed in Sect. 5.3.

In order to linearly decompose the residual spectra based on column densities obtained from the DOAS fit, a system of linear equations was set up to determine contributions $\boldsymbol{v}_{i}$ to the residual spectra $\mathbf{R}$ that are correlated with the column densities $\boldsymbol{S}_{i}$. The residual spectrum $\boldsymbol{v}_{\text {Ring, which is found to }}$ correlate with the Ring signal $\boldsymbol{S}_{\text {Ring, }}$, is then expected to contain the residual structures caused by VRS, independently of potential influences of other absorbers on the residual spectra. Insufficiently modelled absorption cross-sections of the absorber $i$ are found in $\boldsymbol{v}_{i}$ if the respective dSCDs are not strongly correlated.

This approach is based on the following procedure

1. The complete M91 MAX-DOAS data set was fitted from 420 to $440 \mathrm{~nm}$ to avoid the main water vapour absorptions at 416 and $442 \mathrm{~nm}$. The retrieval was the same as in the first analysis (see Table 6), but without the VRS 

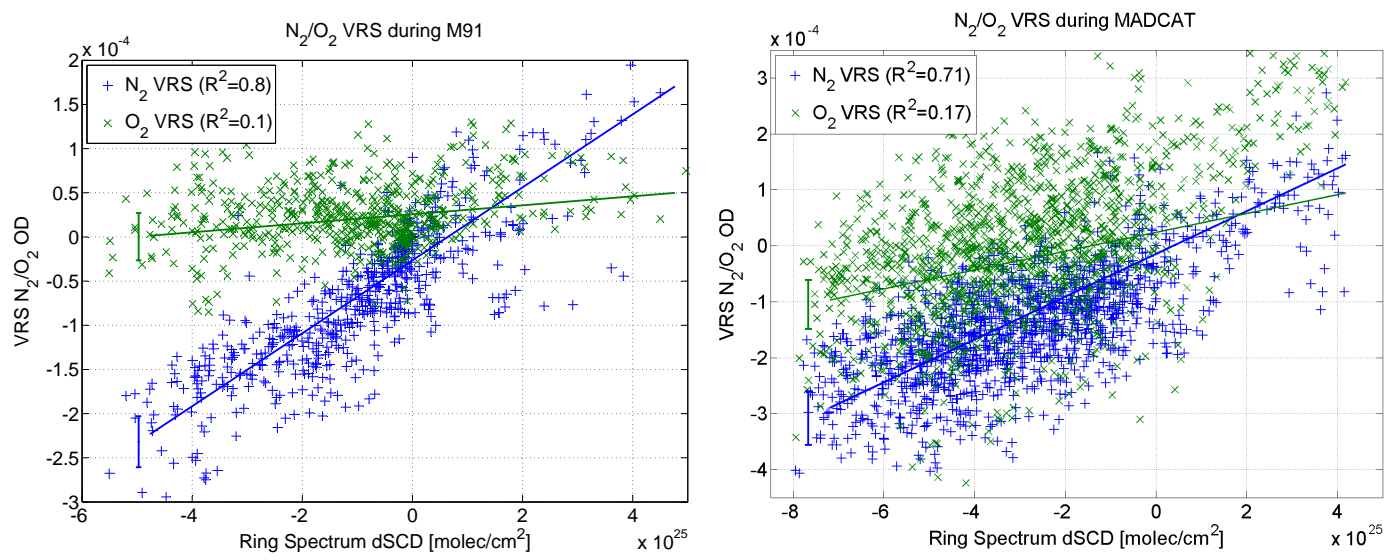

Figure 6. (left) Fit coefficients for Ring and vibrational Raman correction spectrum for $\mathrm{N}_{2}$ and $\mathrm{O}_{2}$ from 702 co-added elevation sequences from the M91 campaign. The VRS axis shows the optical depth of the of the Raman-remapped Ca lines. The resulting relative size of the RRS and VRS cross-sections are listed in Table 9. The intercept of the linear fits is in both cases within the typical measurement error shown as error bars on the left. (right) The same plot from 3264 co-added elevation sequences from the MAD-CAT campaign.

Table 9. Cross-sections for different contributions to Raman scattered light. Absolute values are often listed as well as relative contributions, compared to RRS. The cross-sections were scaled according to the atmospheric ratio of 80 and $20 \%$ for $\mathrm{N}_{2}$ and $\mathrm{O}_{2}$. These values are compared to the results from MAX-DOAS measurements during M91, directly from Fig. 6 and derived from the solution of a system of linear equations and resulting in a fit, which is shown in Fig. 8. The spectrum obtained from the linear system of equations had an $1 \sigma$-error of about $10 \%$. The VRRS contributions were not significant in either case. The theoretical cross-sections were calculated using Eq. (3) at $433 \mathrm{~nm}$ for RRS and at $393 \mathrm{~nm}$ for VRS.

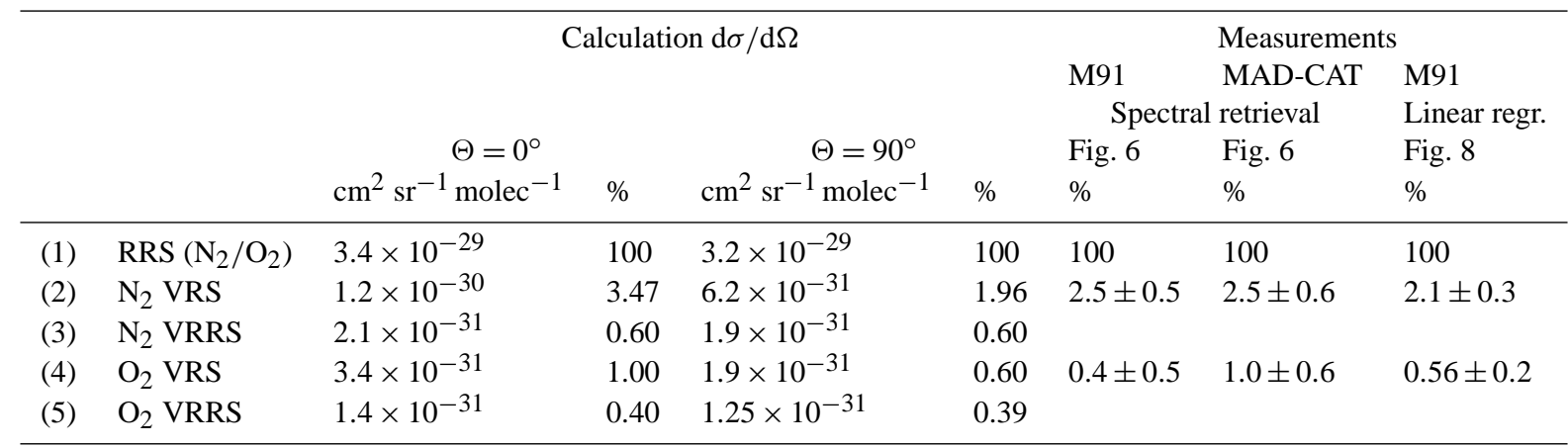

correction spectra and based on individual spectra with an exposure time of $1 \mathrm{~min}$.

2. Only fits with a RMS of $<4 \times 10^{-4}$ were used for the multi-linear regression.

3. All channels $j$ from the residual spectra $i$ were stored in the matrix $\mathbf{R}=R_{i j}$.

4. Regressors were the dSCDs $S$ calculated in the first step, except the magnitude of the rescaled $\left(\lambda^{4} / \lambda_{0}^{4}-1\right)$ Ring spectrum, as this is only a correction of the Ring spectrum. Also the size of the intensity offset correction, exposure time and number of scans are used as regressors. Scan number and exposure time could indicate here a contribution to the residuals from offset and dark current spectra. Together, these vectors form the matrix $\mathbf{A}$.
$\mathbf{A}^{\mathrm{T}} \cdot \mathbf{V}=\left(\boldsymbol{S}_{\text {Ring }} \boldsymbol{S}_{\mathrm{H}_{2} \mathrm{O}} \ldots\right)^{\mathrm{T}} \cdot\left(\boldsymbol{v}_{\text {Ring }} \boldsymbol{v}_{\mathrm{H}_{2} \mathrm{O}} \ldots\right)=\mathbf{R}$

The overdetermined system of linear equations (Eq. 20) was solved for $\mathbf{V}$ using a least-squares approach, minimizing $\left|\mathbf{A}^{\mathrm{T}} \cdot \mathbf{V}-\mathbf{R}\right|_{2}$. This yields $\mathbf{V}=\left(\mathbf{A} \mathbf{A}^{\mathbf{T}}\right)^{-1} \mathbf{A} \mathbf{R}$. The resulting correction $\boldsymbol{v}_{\text {Ring }}$ corresponding to the Ring dSCD $\boldsymbol{S}_{\text {Ring }}$ was then fitted with the already included absorbers from the original fit scenario and additionally the pseudo cross-section for vibrational and vibrational-rotational Raman scattering of $\mathrm{N}_{2}$ and $\mathrm{O}_{2}$. This fit is shown in Fig. 8. Adding the other absorbers to the fit is necessary due to possible compensation of residual structures due to VRS by other absorbers within the first fits to obtain the residuals. In other vectors corresponding to other absorbers or parameters a significant contribution of the structure associated with $\operatorname{VRS}\left(\mathrm{N}_{2} / \mathrm{O}_{2}\right)$ was not found. The vector corresponding to the intensity offset correction 


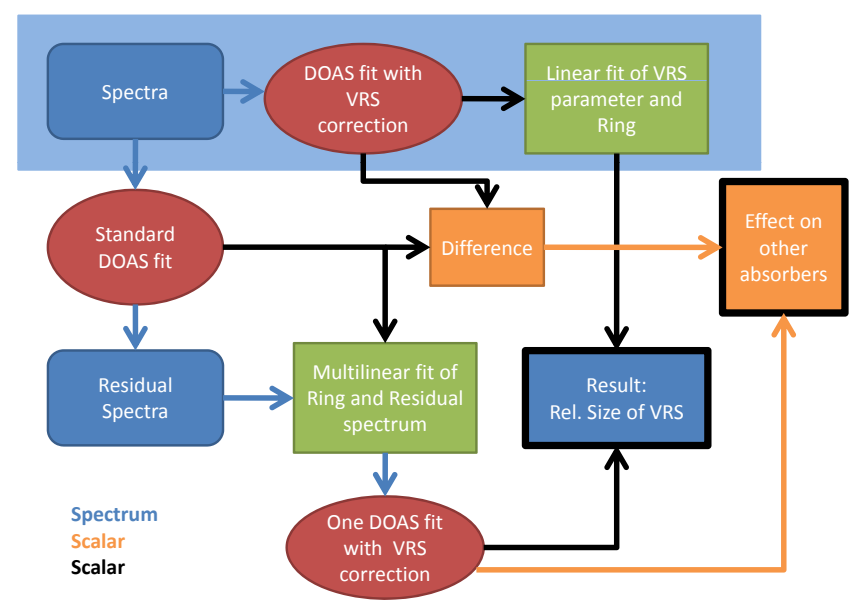

Figure 7. The first line of this diagram shows the procedure which led to Fig. 5: the VRS correction spectrum is added to the fit scenario, applied to all spectra and then the obtained fit coefficients are correlated with the Ring signal. The other approach (Sect. 4.2) uses a standard DOAS fit (without VRS correction), correlates the residuals with the obtained coefficients from the fit and then uses this result to identify a VRS correction spectrum and its coefficients in one final DOAS fit, which is shown in Fig. 8.

could have contained some contribution of $\operatorname{VRS}\left(\mathrm{N}_{2} / \mathrm{O}_{2}\right)$, as a part of it can be compensated by the intensity offset correction; however, no correlation of the magnitude of intensity offset correction and Ring signal was observed. We assume that the intensity offset correction is mainly affected by instrumental stray light, which, for example, depends on the colour index of the measured spectrum.

Despite the significantly better detection of the VRS signal of $\mathrm{O}_{2}$ and $\mathrm{N}_{2}$, the contribution of VRRS of both species could not be disentangled from the intensity offset correction.

The fit of the Ring-correlated residual structure shown in Fig. 8 yields more information than only the contribution of VRS to the observed OD; it also yields approximations for the changes of other involved trace gases in the respective spectral region, a factor with which the Ring signal can be multiplied to obtain the averaged effect on $\mathrm{NO}_{2}$; for example, the fit yields a $\mathrm{NO}_{2}$ fit coefficient of $7.65 \times 10^{-12}$. For a large Ring signal of $5 \times 10^{25} \mathrm{molec} \mathrm{cm}^{-2}$ this results in a change of $\mathrm{NO}_{2}$ dSCDs of $(3.8 \pm 0.4) \times 10^{14} \mathrm{molec} \mathrm{cm}^{-2}$. This is larger than the estimate from individual fits shown in Fig. 9, because Fig. 9 combines all measurements with different Ring dSCDs.

The main advantage of this approach is that it allows for the obtainment of an average over the residual structures associated with a certain absorber over the whole period of a campaign, e.g. a month or a year for a sufficiently stable instrument. This can reduce the influence of photon shot noise to a minimum. Furthermore an identification of the VRS signature from spectral data is possible for $\mathrm{N}_{2}$ as well as for the weaker $\mathrm{O}_{2}$ signal, which was not found to be significant in Fig. 6 for individual elevation sequences.

\section{Discussion}

The obtained results from measurements listed in Table 9 are in agreement with calculations based on Eq. (14) as shown in Eq. (9). Since the average scattering angle is also between 0 and $180^{\circ}$, the relative size of the VRS contributions is found between both extrema of $\mathrm{d} \sigma(\Theta) / \mathrm{d} \Omega$ at 0 and $90^{\circ}$. While the impact of VRS of $\mathrm{N}_{2}$ is clearly detected, the spectral signature of VRS of $\mathrm{O}_{2}$ remains close to the instruments detection limit. For M91, it can be clearly detected by analysing all residual spectra as described in Sect. 4.2.

The results agree for both campaigns, M91 over the ocean and MAD-CAT over land, which excludes an interference with VRS of liquid water. VRS of liquid water has furthermore a different spectral signature due to its broad Raman response (compare Fig. 2) and the narrow response of $\operatorname{VRS}\left(\mathrm{N}_{2}\right)$ can be identified from DOAS fits, as this leads to a Fraunhofer ghost of the calcium lines at $393 \mathrm{~nm}$, shifted to $433 \mathrm{~nm}$. Additionally the signal for VRS of $\mathrm{N}_{2}$ and $\mathrm{O}_{2}$ are linearly correlated with the magnitude of the Ring signal, which underlines the fact, that it is indeed an atmospheric effect.

\subsection{Impact on trace gas retrievals}

Ignoring the potentially significant impact of VRS can lead to systematic biases in the spectral evaluation. Since IO, $\mathrm{NO}_{2}$, water vapour and glyoxal are trace gases typically absorbing in a spectral range which is mainly affected by VRS, its effect is exemplary studied for these trace gases for our M91 data set. Also here 16 elevation sequences were co-added in order to reduce the overall fit errors. Fit results with an RMS larger than $2 \times 10^{-4}$ were not used. We observed an agreement of the results when not co-adding elevation sequences.

We found that correcting for the effect of VRS will reduce the total RMS of the fit residual for a large Ring signal and thus in most cases also the fit error. It does not significantly lower the RMS for spectra with small Ring signals. Whether the correction has an impact on the retrieved column densities has to be tested for each trace gas and also for different spectral resolutions of the respective MAX-DOAS instruments, which can have an influence on the way in which the neglected apparent OD was compensated for. The difference of the squares of the RMS $\chi^{2}$ of the evaluation with and without correcting for VRS is expected to have a linear relationship with the square of the Ring signal, $R$ :

$\Delta \chi^{2}=a \cdot R^{2}$.

This relation is found in MAX-DOAS data, for example, from M91, with $a=(0.25 \pm 0.05) \times 10^{-8} /(5 \times$ $10^{25}$ molec $\left.\mathrm{cm}^{-2}\right)^{2}$ for the wavelength interval $420-438 \mathrm{~nm}$, 

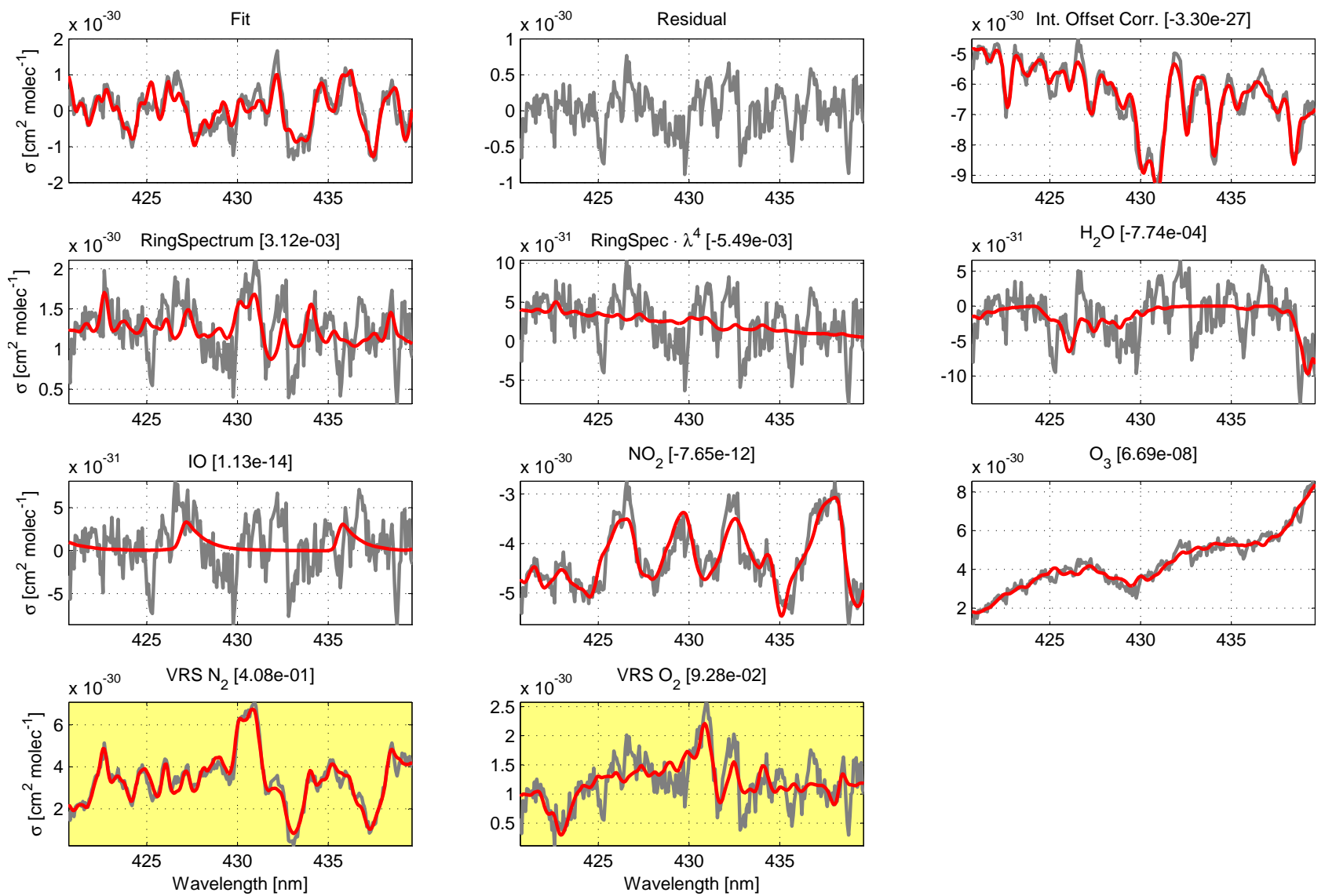

Figure 8. Fit of the Ring-dSCD-correlated residual structure obtained from a linear regression of residual spectra and corresponding dSCDs. The cross-sections for $\mathrm{IO}$, water vapour, $\mathrm{NO}_{2}$ and $\mathrm{O}_{3}$ are from the original fits from which the residual spectra were used to solve the system of linear equations. Their coefficients in the fit above are thus dimensionless or could be written as molec $\mathrm{cm}^{-2}$ per molec $\mathrm{cm}^{-2}$ Ring-dSCD. The VRS spectra are calculated from a solar atlas. The VRRS $\left(\mathrm{N}_{2} / \mathrm{O}_{2}\right)$ component is not significant here in the sense that it is not distinguishable from the contribution of the intensity offset correction, which is usually necessary to compensate for instrumental stray light. The spectrum for $\operatorname{VRS}\left(\mathrm{N}_{2}\right)$ is detected at a size which corresponds to 29 times the fit error, the contribution of $\operatorname{VRS}\left(\mathrm{O}_{2}\right) 8$ times.

effectively reducing the RMS of a fit residual of $1 \times 10^{-4}$ by about $15 \%$ for a Ring signal of $5 \times 10^{25} \mathrm{molec}^{-2}$. In other words, if no VRS spectrum is included, the minimum possible RMS for a DOAS fit showing a Ring signal of this magnitude is larger than $5 \times 10^{-5}$. In this case, $30 \%$ of the VRS signal is already compensated for by other absorbers and the intensity offset correction.

The following subsections show the impact on the spectral retrieval of different trace gases when neglecting this effect. It may vary depending on fit settings and the spectral resolution of the instrument. Within each of the comparisons the same retrieval settings and intervals were used, once without and once with the correction for VRS of $\mathrm{N}_{2}$ and $\mathrm{O}_{2}$. From the resulting dSCDs of these two fits the impact of VRS was calculated.

\subsubsection{Influence of VRS on the retrieval of IO}

To estimate the influence of having ignored the effect of VRS of $\mathrm{N}_{2}$, MAX-DOAS data from M91 was reanalysed for IO in the wavelength range of $418-438 \mathrm{~nm}$ with and without VRS and VRRS $\left(\mathrm{N}_{2}\right)$ correction spectra. Except for the wavelength range, the fit used the same settings as used for the detection of VRS of air listed in Table 6. Using an example measurement spectrum with $2 \times 10^{-4}$ differential optical depth caused by VRS from 432 to $438 \mathrm{~nm}$, including the correction spectra led to a decrease of the fit error by $25 \%$.

Leaving the size of the correction independent of the Ring spectrum showed that the IO dSCD is independent of the amount of structures caused by VRS of $\mathrm{N}_{2}$ within the typical IO measurement error of $1.5 \times 10^{12} \mathrm{molec} \mathrm{cm}^{-2}$.

The use of the linear regression method and the fit shown in Fig. 8, while assuming a maximum Ring signal of $5 \times$ $10^{25} \mathrm{molec}^{-2}$, corresponds to a change in IO dSCD of 
$6 \times 10^{11} \mathrm{molec}^{-2}$, which is also within the typical IO measurement errors.

The effect of the VRRS $(\Delta v=1, \Delta J \neq 0)$ transitions was not observed to be correlated with RRS and could not be distinguished from the contribution by the intensity offset correction. Therefore, its impact on IO dSCDs was not studied.

\subsubsection{Influence of VRS on the retrieval of $\mathrm{NO}_{2}$}

$\mathrm{NO}_{2}$ can be evaluated in the same wavelength range as IO, from 418 to $438 \mathrm{~nm}$. In this wavelength range, $\mathrm{NO}_{2}$ has a relatively large absorption cross-section of $\mathrm{NO}_{2}$, and the influence of water vapour absorption is minimal. When retrieving tropospheric $\mathrm{NO}_{2} \mathrm{dSCD}$, negative $\mathrm{NO}_{2}$ values are often observed in clean and remote areas. Since these negative dSCD are also frequently observed close to local noon, this excludes an effect of a changing AMF (air mass factor) of stratospheric $\mathrm{NO}_{2}$ within one elevation sequence. One reason for this negative $\mathrm{NO}_{2}$ dSCDs can be VRS of liquid water, as discussed in Peters et al. (2014). Its signal is strong for regions of the ocean with clear water for elevation angles close to the horizon or downward-looking geometries. In the M91 MAX-DOAS data set in the Peruvian upwelling region, neither the spectral signature of liquid water VRS nor liquid water was found (see Sect. 3.2.1).

Including the VRS correction spectra can lead to a reduction of the fit error by $\approx 15 \%$ and furthermore the $\mathrm{NO}_{2}$ dSCD changes by $4 \times 10^{14}$ molec $\mathrm{cm}^{-2}$ per $2 \times 10^{-4}$ $\operatorname{VRS}\left(\mathrm{N}_{2}\right)$ contribution. This corresponds typically to a difference of $20 \mathrm{ppt} \mathrm{NO}_{2}$ and can be thus significant for background measurements of $\mathrm{NO}_{2}$ in clean areas (e.g. Lee et al., 2010). Figure 9 shows two histograms for $\mathrm{NO}_{2} \mathrm{dSCDs}$ from M91, without (Reference fit) and with including a correction spectrum for VRS of $\mathrm{N}_{2}$ and $\mathrm{O}_{2}$.

Usually a wider fit interval (e.g. Richter et al., 2011) or a fit interval above $450 \mathrm{~nm}$ (e.g. Peters et al., 2012) is used to fit the absorptions of tropospheric $\mathrm{NO}_{2}$, which will then reduce the relative effect from $\operatorname{VRS}\left(\mathrm{N}_{2}\right)$, but the instrument needs to cover this wavelength range and the significantly stronger influence of water vapour absorption in this spectral range needs to be considered. The same analysis as shown in Fig. 9 for a fit range from 432 to $460 \mathrm{~nm}$ leads also to an underestimation of $\mathrm{NO}_{2}$ dSCDs. A shift of the mean dSCD from $1.24 \times 10^{14}$ molec cm $^{-2}$ without including $\operatorname{VRS}\left(\mathrm{N}_{2}\right)$ and $\operatorname{VRS}\left(\mathrm{O}_{2}\right)$ correction spectra to a mean dSCD of $1.72 \times 10^{14}$ molec $\mathrm{cm}^{-2}$ when including the correction is observed and is therefore within the typical fit error of $0.8 \times 10^{14}$ molec cm $^{-2}$.

\subsubsection{Influence of VRS on the retrieval of glyoxal}

To retrieve glyoxal, a fit window from 432 to $460 \mathrm{~nm}$ was used, with and without including $\mathrm{N}_{2}$-VRS (see also Table 6). Including a correction spectrum for $\mathrm{N}_{2}$-VRS led to a reduction of fit RMS of $0-20 \%$, the glyoxal fit error was re-

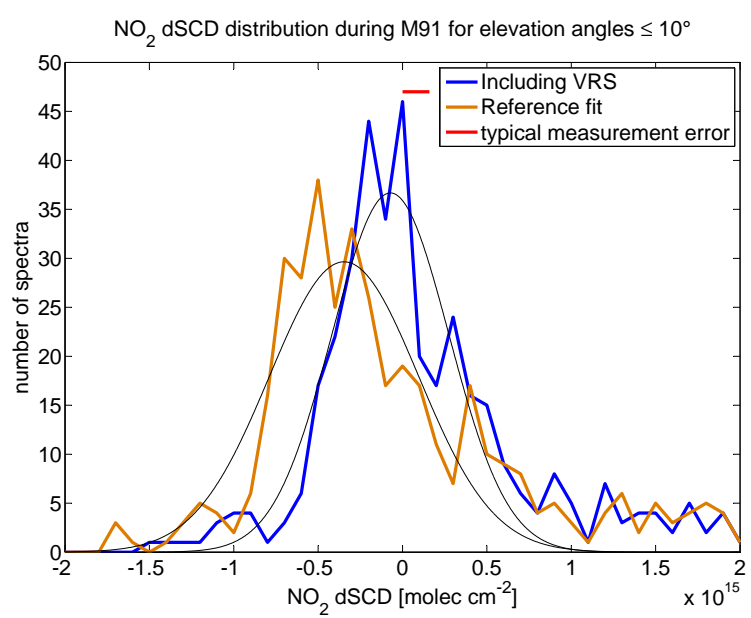

Figure 9. Histogram of $\mathrm{NO}_{2} \mathrm{dSCDs}$ in the wavelength range of $418-438 \mathrm{~nm}$ illustrating the influence of $\operatorname{VRS}\left(\mathrm{N}_{2} / \mathrm{O}_{2}\right)$ on the spectral retrieval of $\mathrm{NO}_{2}$. Twice the fit error is shown as a line on the top of the figure. The centre of the fitted gaussian curves is shifted from $(-3.5 \pm 0.4) \times 10^{14}$ molec cm $^{-2}$ to $(-0.7 \pm 0.3) \times 10^{14}$ molec cm $^{-2}$.

duced by the same amount. RRS Ring spectrum and $\mathrm{N}_{2}$ VRS also correlated in this wavelength window, despite the large water vapour absorption. The glyoxal dSCD increased when including the $\mathrm{N}_{2}$-VRS for strong Ring spectrum signals of $5 \times 10^{25} \mathrm{molec} \mathrm{cm}^{-2}$ by $6 \times 10^{13}$ molec $\mathrm{cm}^{-2}$ and is thus clearly within the measurement error of typically $5 \times 10^{14} \mathrm{molec}^{-2}$. All other influences, such as water vapour and $\mathrm{O}_{4}$ absorption, have a far stronger influence on the spectral retrieval of glyoxal.

\subsubsection{Influence of VRS on the retrieval of water vapour}

The same settings as for glyoxal were used to estimate the influence of VRS on retrieved water vapour column densities. The observed changes were found to be below $1.5 \times 10^{21}$ molec $\mathrm{cm}^{-2}(0.5 \%)$ for typical dSCDs of $(3 \pm 1) \times$ $10^{23} \mathrm{molec}^{-2}$ at telescope elevation angles below $10^{\circ}$. This is the same magnitude as typical fit errors, which were reduced by $0-10 \%$.

For the narrower fit range of $420-440 \mathrm{~nm}$, which is used for the evaluation shown in Fig. 5, the changes in apparent water vapour absorption are larger due to the smaller water vapour cross-section. Here the VRS would have changed the water vapour dSCD by up to $5 \times 10^{22}$ molec $\mathrm{cm}^{-2}$ (typically more than $10 \%$ ) for a Ring signal of $5 \times 10^{25} \mathrm{molec} \mathrm{cm}^{-2}$.

The results from Lampel et al. (2015) reporting significant deviations of the relative absorption strengths for water vapour absorption in the blue wavelength range do not change significantly when applying correction spectra for $\mathrm{N}_{2}$ and $\mathrm{O}_{2}$ VRS in the spectral retrieval of the MAX-DOAS data. 


\subsection{Implications for other wavelength intervals}

The influence of VRS on the observed differential OD at 433 and $436 \mathrm{~nm}$ is directly visible due to the high OD of the Ca-II-Fraunhofer lines, combined with overall small residual sizes due to large amounts of available light.

Towards shorter wavelengths, the amount of Raman scattered light scales with $1 / \lambda^{4}$ according to Eq. (14). This is compensated, however, by the fact that Fraunhofer lines below $390 \mathrm{~nm}$ are less pronounced. In the wavelength range of $332-380 \mathrm{~nm}$ it was not possible to clearly identify the contribution of VRS of $\mathrm{N}_{2} / \mathrm{O}_{2}$. The residual spectra were dominated by systematic residual structures correlated with the $\mathrm{dSCD}$ of $\mathrm{O}_{4}$ with typical ODs of $(4-8) \times 10^{-4}$ for lightpath lengths of $\approx 10 \mathrm{~km}$. The structures were observed independently of the employed $\mathrm{O}_{4}$ literature cross-section. We expect an apparent differential OD due to the contribution by VRS of $\mathrm{N}_{2}$ to measured ODs of about $3 \times 10^{-4}$ at $360 \mathrm{~nm}$ (see also Fig. 3) for a large Ring signal of $5 \times 10^{25} \mathrm{molec} \mathrm{cm}^{-2}$.

If the incident light was attenuated by any strong absorber before being scattered inelastically, then strong absorbers such as ozone, water vapour or $\mathrm{NO}_{2}$ need to be considered.

But even without strong Fraunhofer or absorption lines, this effect contributes to the observed differential OD according to Eq. (18). However, constant or polynomial intensity offset corrections are included in typical spectral evaluations of DOAS measurements, compensating in this case for most of the contribution of VRS and VRRS.

\subsection{Recommended corrections}

Correction spectra for VRS of $\mathrm{N}_{2}$ and $\mathrm{O}_{2}$ need to be included especially in the spectral retrievals of $\mathrm{NO}_{2}$, IO and glyoxal, but also water vapour in the blue spectral range, whenever wavelengths between 430 and $440 \mathrm{~nm}$ are included and systematic residual structures are smaller than the optical depths attributed to VRS of $\mathrm{N}_{2}$ and $\mathrm{O}_{2}$. For a residual RMS of $1 \times 10^{-4}$ an improvement of the RMS of up to $15 \%$ was observed.

Since the atmospheric $\mathrm{O}_{2} / \mathrm{N}_{2}$ ratio is constant (at the precision relevant to correcting spectra for VRS contributions), it is advisable as a first approximation to include only a single combined $\mathrm{N}_{2}+\mathrm{O}_{2}$-spectrum compensating for VRS contributions to measured intensities. The contribution by VRRS is mostly proportional to the VRS signal and can therefore be added to the VRS correction spectrum. On the other hand, the contribution of VRRS is relatively smooth (compare Fig. 2) due to the rotational shifts of the transitions and a large part is already compensated in fit settings by the intensity offset correction. Given a Ring signal with an OD of $2 \%$, for example, this translates to an additionally measured intensity due to VRRS of $0.8 \times 10^{-4}$. Due to the Raman remapped $\mathrm{Ca}$ lines the largest variations are expected for the spectral region between 414 and $440 \mathrm{~nm}$. The effect is already corrected by the intensity offset correction except for a remain- ing part of 30-50\%, which translates to total differential ODs of $<0.4 \times 10^{-4}$. This is currently negligible for most groundbased measurements, but this effect might need to be considered for geometries where a strong filling-in of Fraunhofer lines is observed ${ }^{2}$.

Due to the observed correlation of the spectral signature of VRS scattering on $\mathrm{N}_{2}$ and the Ring dSCD shown in Fig. 5, a direct correction of the Ring spectrum together with the VRS signal seems reasonable, at least in the spectral ranges where an effect has been observed. The actual values of the cross-sections can be found, for example, in Table 9. This would allow furthermore to correct for VRRS scattering, which is also expected to behave in the same way as the Ring spectrum, but is often (by coincidence) corrected by the intensity offset correction (see Eq. 18), as estimated above. This correction of the Ring spectrum would therefore improve how the intensity offset correction can be interpreted, which usually has been introduced in the first place to compensate for instrumental stray light. The contribution of the VRRS on $\mathrm{O}_{2}$ and $\mathrm{N}_{2}$ can then be removed from the intensity offset correction polynomial, because the dominating factor for determining the Ring spectrum dSCD is the actual RRS contribution, which is about 50 times larger.

However, the following points need to be considered:

1. Vibrational Raman scattering leads to a red-shift of solar radiation, thus the ratio of vibrational Raman scattered and elastically scattered light is influenced by the wavelength dependency of the aerosol extinction and Rayleigh scattering. For the case of rotational Raman scattering (the Ring effect) this is inherently compensated for, since the frequency shift due to RRS is not significant for the wavelength dependence of the aerosol extinction. For the shift of $40 \mathrm{~nm}$ of $\mathrm{N}_{2}$ VRS from the Ca-II K Fraunhofer line at $393 \mathrm{~nm}$, significant relative intensity differences at $393 / 433 \mathrm{~nm}$ can be observed for different measurement geometries and/or aerosol loads. During M91, relative intensities at 390 and $432 \mathrm{~nm}$ (the so-called colour-index $\mathrm{CI}(390,432 \mathrm{~nm})$ ) were observed between 0.3 and 0.8 for zenith sky measurements, even more if the complete elevation angle sequence is considered. This relation translates directly to the size of VRS correction spectrum via Eq. (18). Therefore, a direct correction of the Ring spectrum is not possible in general, if not considering these effects explicitly. The same argumentation can be applied for separating the influence of $\operatorname{VRS}\left(\mathrm{N}_{2}\right)$ and $\operatorname{VRS}\left(\mathrm{O}_{2}\right)$, since the wavelength shifts are different. However, the influence of $\operatorname{VRS}\left(\mathrm{O}_{2}\right)$ is hardly detected in current measurement spectra. A potential dependence of VRS $\left(\mathrm{N}_{2}\right)$-OD on the colour-index was not observed in measurements.

\footnotetext{
${ }^{2}$ All calculations for a spectral resolution of the instrument of $0.5 \mathrm{~nm}$.
} 
2. The phase functions of RRS, VRS and VRRS differ. Different contributions proportional to $\overline{\alpha_{i j}^{2}}$ and $\overline{\alpha_{i i}^{2}}$ in the cross-section correspond to different phase functions, thus the resulting filling-in does not need to be correlated exactly. This needs to be modelled in detail to estimate the error made when assuming the same phase functions. Since no explicit dependence of the relative VRS contribution to the Ring signal depending on the measurement geometry was observed during 1 month of measurements during M91 shown in Table 9 , it is estimated to be below $20 \%$ of the OD of the VRS of $\mathrm{N}_{2}$. For a typical variation of the Ring dSCD of $3 \times 10^{25} \mathrm{molec}^{-2}$ this error is therefore found to be below $2 \times 10^{-5}$ peak-to-peak in the wavelength range between 430 and $440 \mathrm{~nm}$, where the largest spectral structures were detected. This is 5 times smaller than the typical sizes of residual spectra of current MAX-DOAS evaluations.

A way to avoid these points is to use a measured spectrum to calculate the correction spectra, which includes the effects due to changes in radiative transfer, such as aerosol load and measurement geometry. When using measured spectra, this would require the same quantum efficiency of the instrument at both wavelengths or a radiometrically calibrated instrument, as well as a constant instrument slit function. This is typically not the case.

It is therefore recommended to include the correction spectrum for VRS of $\mathrm{N}_{2}$ without including the contribution from VRRS, calculated based on a solar atlas. Correction for VRS of $\mathrm{O}_{2}$ is only needed if the RMS of the residual is significantly below $10^{-4}$.

\section{Conclusions}

Vibrational Raman scattering of $\mathrm{N}_{2}$ and $\mathrm{O}_{2}$ can contribute significantly to observed optical depths in passive DOAS applications. This was shown for ground-based and ship-based MAX-DOAS observations from two different campaigns using two different MAX-DOAS instruments and is expected to contribute in the same amount to other passive DOAS techniques, such as airborne or satellite measurements. Optical depths due to VRS Fraunhofer ghosts were observed to amount to up to $3 \times 10^{-4}$ in the blue spectral region. The strong Ca Fraunhofer lines at 393 and $396 \mathrm{~nm}$ are shifted by VRS of $\mathrm{N}_{2}$ to 433 and $436 \mathrm{~nm}$, where they are observed as Fraunhofer ghosts. Their magnitude correlates well $\left(R^{2}=0.8\right.$ for M91, $R^{2}=0.7$ for MAD-CAT) with the magnitude of inelastic scattering due to rotational Raman scattering (Ring effect). The relative contribution of the cross-section of VRS of $\mathrm{N}_{2}$ to the cross-section of RRS of $2.3 \%$ is in agreement with expected values from the theory $(2-3.5 \%$, depending on the measurement geometry). The detection of VRS of $\mathrm{O}_{2}$ is close to its detection limit and amounts to an averaged contribution of $0.55 \pm 0.30 \%$ of RRS, and thus it is also in agreement with expected values from the theory (0.6$1.0 \%$ ). The individual MAD-CAT result for the contribution of VRS of $\mathrm{NO}_{2}$ is also still in agreement with expected values $(1.0 \%)$, but compared to the contribution of VRS of $\mathrm{N}_{2}$, a lower value (as for M91) would have been expected. The reason for this overestimation could be interferences with large absorption of $\mathrm{NO}_{2}$ and the absorption of glyoxal, but could also be caused by the lower spectral resolution and the less constant instrument function width of the compact spectrometer used during MAD-CAT, compared with the Acton 300i during M91. A contribution of vibrational rotational Raman scattering (VRRS) of air could not be identified for the used data sets.

In spectral regions without large Fraunhofer ghost structures the intensity offset polynomial typically used in DOAS evaluations can compensate for most of this effect. Depending on the magnitude of the Ring effect, the correction of $\operatorname{VRS}\left(\mathrm{N}_{2} / \mathrm{O}_{2}\right)$ leads to a reduction of the fit RMS (see Eq. 21): the RMS of a fit residual of $1 \times 10^{-4}$ is reduced by about $15 \%$ for a Ring signal of $5 \times 10^{25} \mathrm{molec} \mathrm{cm}^{-2}$ when considering $\operatorname{VRS}\left(\mathrm{N}_{2} / \mathrm{O}_{2}\right)$ in the spectral retrieval. For measurements with residual structures significantly larger than those attributed here to $\operatorname{VRS}\left(\mathrm{N}_{2} / \mathrm{O}_{2}\right)$, it is not advisable to include the correction spectra in the fit, as it will introduce additional degrees of freedom to the fit. This could lead to erroneous results. Nevertheless, it is possible to detect this effect using a compact spectrometer, as shown here for the MAD-CAT data set.

The apparent OD caused by VRS of $\mathrm{N}_{2}$ and $\mathrm{O}_{2}$ can influence the spectral retrieval of various trace gases. For instance, the large Ca-II-Fraunhofer lines at 393.4 and $396.8 \mathrm{~nm}$ lead to ghost lines at 433.1 and $437.2 \mathrm{~nm}$. The additional measured intensity can influence the spectral retrieval of $\mathrm{NO}_{2}$, water vapour, IO and glyoxal. This influence was studied for ship-based MAX-DOAS measurements. While the influence on the total magnitude of water vapour, IO and glyoxal column densities was below the detection limit, a significant and systematic negative offset of $\mathrm{NO}_{2} \mathrm{dSCDs}$ by up to $4 \times 10^{14} \mathrm{molec}^{-2}$ was observed. In all cases, the fit errors were reduced by up to $20 \%$ by including the VRS spectrum in the DOAS fit. The observed ODs attributed to VRS of $\mathrm{N}_{2}$ between 430 and $440 \mathrm{~nm}$ are of similar size as reported absorptions of IO in the remote marine boundary layer (e.g. Großmann et al., 2013) and Antarctica (e.g. Frieß et al., 2010) in the same wavelength range.

The systematic biases introduced into DOAS evaluations of different trace gases by neglecting the effect of vibrational Raman scattering shows once more the need for highprecision absorption measurements of trace gases and thorough statistical analysis of residual spectra. Even if individual measurements hardly allow the identification of systematic structures, systematic contribution in the residual spectra might still be identified and point towards possible improvements. Future advances in DOAS evaluations as well as improved DOAS instruments are expected to further reduce the 
magnitude of residual structures and thus improve detection limits. While the correction of VRS effects already improves the evaluation of several trace species, this correction will be even more important in future advanced DOAS evaluations.

\section{Supplement}

We provide the VRS correction spectra calculated from a solar atlas by Chance and Kurucz (2010) using Eq. (14) for vacuum wavelengths. It is given in $\mathrm{cm}^{2} \mathrm{molec}^{-1}$. As the shape of the correction spectrum depends on the instrument function of the spectrometer, the Raman spectrum and the solar atlas are given to allow the calculation of the correction spectrum according to Eq. (19). This is necessary, since division and convolution do not commute. The spectra are interpolated to a common wavelength grid with a spectral resolution of $0.01 \mathrm{~nm}$.

\section{The Supplement related to this article is available online at doi:10.5194/amt-8-3767-2015-supplement.}

Acknowledgements. We thank H. Haug for laying the foundations for this work in his diploma thesis (Haug, 1996). We thank Stefan Schmitt, Julia Remmers, two anonymous reviewers and the editor for valuable comments and suggestions.

We thank the captain, officers and crew for support during research cruise M91.

We want to thank the organizers of the Multi Axis DOAS Comparison campaign for Aerosols and Trace gases (MAD-CAT) in summer 2013 (http://joseba.mpch-mainz.mpg.de/mad_cat.htm), especially Julia Remmers and Thomas Wagner.

We thank the German Science foundation DFG for its support within the core program METEOR/MERIAN.

We thank the German ministry of education and research (BMBF) for supporting this work within the SOPRAN (Surface Ocean Processes in the Anthropocene) project (Förderkennzahl: 03F0662F) which is embedded in SOLAS.

We thank the authorities of Peru for the permission to work in their territorial waters.

We thank GEOMAR for logistic support

Rich Pawlowicz is acknowledged for providing the m_map toolbox.

The article processing charges for this open-access publication were covered by the Max Planck Society.

Edited by: A. Richter

\section{References}

Bange, H.: Surface ocean - lower atmosphere study (SOLAS) in the upwelling region off Peru - cruise no. M91, DFGSenatskommission fuer Ozeanographie, METEOR-Berichte, Bremen, Germany, 91, 69 pp., doi:10.2312/cr_m91, 2013.

Bates, D.: Rayleigh scattering by air, Planet. Space Sci., 32, 785790, 1984.

Burrows, J., Platt, U., Chance, K., Vountas, M., Rozanov, V., Richter, A., Haug, H., and Marquard, L.: Study of the Ring Effect, European Space Agency, Noordivijk, the Netherlands, 1996.

Bussemer, M.: Der Ring-Effekt: Ursachen und Einfluß auf die spektroskopische Messung stratosphärischer Spurenstoffe, Diploma thesis, Heidelberg University, Heidelberg, Germany, 1993.

Capone, D. G. and Hutchins, D. A.: Microbial biogeochemistry of coastal upwelling regimes in a changing ocean, Nat. Geosci., 6, 711-717, 2013.

Chance, K. and Kurucz, R.: An improved high-resolution solar reference spectrum for earth's atmosphere measurements in the ultraviolet, visible, and near infrared, J. Quant. Spectrosc. Ra., 111, 1289-1295, 2010.

Coburn, S., Dix, B., Sinreich, R., and Volkamer, R.: The CU ground MAX-DOAS instrument: characterization of RMS noise limitations and first measurements near Pensacola, FL of BrO, IO, and CHOCHO, Atmos. Meas. Tech., 4, 2421-2439, doi:10.5194/amt-4-2421-2011, 2011.

Dinter, T., Rozanov, V. V., Burrows, J. P., and Bracher, A.: Retrieving the availability of light in the ocean utilising spectral signatures of vibrational Raman scattering in hyper-spectral satellite measurements, Ocean Sci., 11, 373-389, doi:10.5194/os-11-3732015, 2015.

Fish, D. and Jones, R.: Rotational Raman scattering and the ring effect in zenith-sky spectra, Geophys. Res. Lett., 22, 811-814, 1995.

Frieß, U., Deutschmann, T., Gilfedder, B. S., Weller, R., and Platt, U.: Iodine monoxide in the Antarctic snowpack, Atmos. Chem. Phys., 10, 2439-2456, doi:10.5194/acp-10-2439-2010, 2010.

Frieß, U., Sihler, H., Sander, R., Pöhler, D., Yilmaz, S., and Platt, U.: The vertical distribution of $\mathrm{BrO}$ and aerosols in the Arctic: measurements by active and passive differential optical absorption spectroscopy, J. Geophys. Res.-Atmos., 116, D00R04, doi:10.1029/2011JD015938, 2011.

Grainger, J. and Ring, J.: Anomalous fraunhofer line profiles, Nature, 193, 762, 1962.

Greenblatt, G. D., Orlando, J. J., Burkholder, J. B., and Ravishankara, A. R.: Absorption measurements of oxygen between 330 and 1140 nm, J. Geophys. Res., 95, 18577-18582, 1990.

Großmann, K., Frieß, U., Peters, E., Wittrock, F., Lampel, J., Yilmaz, S., Tschritter, J., Sommariva, R., von Glasow, R., Quack, B., Krüger, K., Pfeilsticker, K., and Platt, U.: Iodine monoxide in the Western Pacific marine boundary layer, Atmos. Chem. Phys., 13, 3363-3378, doi:10.5194/acp-13-3363-2013, 2013.

Haltrin, V. I. and Kattawar, G. W.: Self-consistent solutions to the equation of transfer with elastic and inelastic scattering in oceanic optics: I. model, Appl. Optics, 32, 5356-5367, 1993.

Haug, H.: Raman-Streuung von Sonnenlicht in der Erdatmosphäre, Diploma thesis, Institut für Umweltphysik, Ruprecht-KarlsUniversität Heidelberg, Heidelberg, 7-90, 1996.

Hermans, C., Vandaele, A. C., Carleer, M., Fally, S., Colin, R., Jenouvrier, A., Coquart, B., and Mérienne, M.-F.: Absorption 
cross-sections of atmospheric constituents: $\mathrm{NO}_{2}, \mathrm{O}_{2}$, and $\mathrm{H}_{2} \mathrm{O}$, Environ. Sci. Pollut. R., 6, 151-158, 1999.

Hönninger, G. and Platt, U.: Observations of $\mathrm{BrO}$ and its vertical distribution during surface ozone depletion at alert, Atmos. Environ., 36, 2481-2489, 2002.

Irikura, K. K.: Experimental vibrational zero-point energies: diatomic molecules, J. Phys. Chem. Ref. Data, 36, 389-397, 2007.

Joiner, J. and Bhartia, P.: The determination of cloud pressures from rotational raman scattering in satellite backscatter ultraviolet measurements, J. Geophys. Res.-Atmos., 100, 23019-23026, 1995.

Joiner, J., Bhartia, P. K., Cebula, R. P., Hilsenrath, E., McPeters, R. D., and Park, H.: Rotational raman scattering (ring effect) in satellite backscatter ultraviolet measurements, Appl. Optics, 34, 4513-4525, 1995.

Kraus, S.: DOASIS - A Framework Design for DOAS, Dissertation, Heidelberg University, Heidelberg, 27-58, 2006.

Lampel, J., Pöhler, D., Tschritter, J., Frieß, U., and Platt, U.: On the relative absorption strengths of water vapour in the blue wavelength range, Atmos. Meas. Tech. Discuss., 8, 5895-5936, doi:10.5194/amtd-8-5895-2015, 2015.

Lee, J. D., McFiggans, G., Allan, J. D., Baker, A. R., Ball, S. M., Benton, A. K., Carpenter, L. J., Commane, R., Finley, B. D., Evans, M., Fuentes, E., Furneaux, K., Goddard, A., Good, N., Hamilton, J. F., Heard, D. E., Herrmann, H., Hollingsworth, A., Hopkins, J. R., Ingham, T., Irwin, M., Jones, C. E., Jones, R. L., Keene, W. C., Lawler, M. J., Lehmann, S., Lewis, A. C., Long, M. S., Mahajan, A., Methven, J., Moller, S. J., Müller, K., Müller, T., Niedermeier, N., O’Doherty, S., Oetjen, H., Plane, J. M. C., Pszenny, A. A. P., Read, K. A., Saiz-Lopez, A., Saltzman, E. S., Sander, R., von Glasow, R., Whalley, L., Wiedensohler, A., and Young, D.: Reactive Halogens in the Marine Boundary Layer (RHaMBLe): the tropical North Atlantic experiments, Atmos. Chem. Phys., 10, 1031-1055, doi:10.5194/acp-10-10312010, 2010.

Long, D. A.: The Raman Effect: A Unified Treatment of the Theory of Raman Scattering by Molecules, John Wiley \& Sons Ltd, Chichester, England, 216, 471-475, 2002.

Mahajan, A. S., Prados-Roman, C., Hay, T. D., Lampel, J., Pöhler, D., Großmann, K., Tschritter, J., Frieß, U., Platt, U., Johnston, P., Kreher, K., Wittrock, F., Burrows, J. P., Plane, J. M., and Saiz-Lopez, A.: Glyoxal observations in the global marine boundary layer, J. Geophys. Res.-Atmos., 119, 6160-6169, 2014.

Murphy, W. F.: The rovibrational Raman spectrum of water vapour v1 and v3, Mol. Phys., 36, 727-732, 1978.

Ortega, I., Koenig, T., Sinreich, R., Thomson, D., and Volkamer, R.: The CU 2-dimensional MAX-DOAS instrument - Part 1: Retrieval of $\mathrm{NO}_{2}$ in 3 dimensions and azimuth dependent OVOC ratios, Atmos. Meas. Tech. Discuss., 7, 11653-11709, doi:10.5194/amtd-7-11653-2014, 2014.

Penney, C. M. and Lapp, M.: Raman-scattering cross sections for water vapor, J. Opt. Soc. Am., 66, 422-425, 1976.

Penney, C. M., Peters, R. L. S., and Lapp, M.: Absolute rotational raman cross sections for $\mathrm{N}_{2}, \mathrm{O}_{2}$, and $\mathrm{CO}_{2}$, J. Opt. Soc. Am., 64, 712-716, 1974.

Peters, E., Wittrock, F., Großmann, K., Frieß, U., Richter, A., and Burrows, J. P.: Formaldehyde and nitrogen dioxide over the remote western Pacific Ocean: SCIAMACHY and GOME-2 validation using ship-based MAX-DOAS observations, Atmos.
Chem. Phys., 12, 11179-11197, doi:10.5194/acp-12-111792012, 2012.

Peters, E., Wittrock, F., Richter, A., Alvarado, L. M. A., Rozanov, V. V., and Burrows, J. P.: Liquid water absorption and scattering effects in DOAS retrievals over oceans, Atmos. Meas. Tech., 7, 4203-4221, doi:10.5194/amt-7-4203-2014, 2014.

Pinardi, G., Van Roozendael, M., Abuhassan, N., Adams, C., Cede, A., Clémer, K., Fayt, C., Frieß, U., Gil, M., Herman, J., Hermans, C., Hendrick, F., Irie, H., Merlaud, A., Navarro Comas, M., Peters, E., Piters, A. J. M., Puentedura, O., Richter, A., Schönhardt, A., Shaiganfar, R., Spinei, E., Strong, K., Takashima, H., Vrekoussis, M., Wagner, T., Wittrock, F., and Yilmaz, S.: MAXDOAS formaldehyde slant column measurements during CINDI: intercomparison and analysis improvement, Atmos. Meas. Tech., 6, 167-185, doi:10.5194/amt-6-167-2013, 2013.

Platt, U. and Stutz, J.: Differential Optical Absorption Spectroscopy, Springer, Berlin, Heidelberg, 91-99, 135-159, 2008.

Platt, U., Marquard, L., Wagner, T., and Perner, D.: Corrections for zenith scattered light DOAS, Geophys. Res. Lett., 24, 1759$1762,1997$.

Pope, R. M. and Fry, E. S.: Absorption spectrum (380-700 nm) of pure water. II. integrating cavity measurements, Appl. Opt., 36, 8710-8723, 1997.

Richter, A., Begoin, M., Hilboll, A., and Burrows, J. P.: An improved $\mathrm{NO}_{2}$ retrieval for the GOME-2 satellite instrument, Atmos. Meas. Tech., 4, 1147-1159, doi:10.5194/amt-4-1147-2011, 2011.

Rizi, V., Iarlori, M., Rocci, G., and Visconti, G.: Raman LIDAR observations of cloud liquid water, Appl. Optics, 43, 6440-6453, 2004.

Rothman, L., Gordon, I., Babikov, Y., Barbe, A., Benner, D. C., Bernath, P., Birk, M., Bizzocchi, L., Boudon, V., Brown, L., Campargue, A., Chance, K., Cohen, E., Coudert, L., Devi, V., Drouin, B., Fayt, A., Flaud, J.-M., Gamache, R., Harrison, J., Hartmann, J.-M., Hill, C., Hodges, J., Jacquemart, D., Jolly, A., Lamouroux, J., Roy, R. L., Li, G., Long, D., Lyulin, O., Mackie, C., Massie, S., Mikhailenko, S., Müller, H., Naumenko, O., Nikitin, A., Orphal, J., Perevalov, V., Perrin, A., Polovtseva, E., Richard, C., Smith, M., Starikova, E., Sung, K., Tashkun, S., Tennyson, J., Toon, G., Tyuterev, V., and Wagner, G.: The HITRAN2012 molecular spectroscopic database, J. Quant. Spectrosc. Ra., 130, 4-50, 2013.

Rozanov, V. V. and Vountas, M.: Radiative transfer equation accounting for rotational raman scattering and its solution by the discrete-ordinates method, J. Quant. Spectrosc. Ra., 133, 603618, 2014.

Schmidt, D. A. and Miki, K.: Structural correlations in liquid water: A new interpretation of ir spectroscopy, J. Phys. Chem. A, 111, 10119-10122, 2007.

Schönhardt, A., Richter, A., Wittrock, F., Kirk, H., Oetjen, H., Roscoe, H. K., and Burrows, J. P.: Observations of iodine monoxide columns from satellite, Atmos. Chem. Phys., 8, 637-653, doi:10.5194/acp-8-637-2008, 2008.

Schrötter, H. and Klöckner, H.: Raman scattering cross sections in gases and liquids, in: Raman Spectroscopy of Gases and Liquids, edited by: Weber, A., Volume 11 of Topics in Current Physics, 123-166, Springer, Berlin, Heidelberg, 1979.

Serdyuchenko, A., Gorshelev, V., Weber, M., Chehade, W., and Burrows, J. P.: High spectral resolution ozone absorption cross- 
sections - Part 2: Temperature dependence, Atmos. Meas. Tech., 7, 625-636, doi:10.5194/amt-7-625-2014, 2014.

Shefov, N. N.: Intensivnosti nokotorykh emissiy sumerochnogo i nochnogo neba (intensities of some emissions of the twilight and night sky), Spectral, electrophotometrical and radar researches of aurorae and airglow, IGY program, section IV, 1, 25, 1959.

Sinreich, R., Coburn, S., Dix, B., and Volkamer, R.: Ship-based detection of glyoxal over the remote tropical Pacific Ocean, Atmos. Chem. Phys., 10, 11359-11371, doi:10.5194/acp-1011359-2010, 2010.

Solomon, S., Schmeltekopf, A. L., and Sanders, R. W.: On the interpretation of zenith sky absorption measurements, J. Geophys. Res.-Atmos., 92, 8311-8319, 1987.

Spietz, P., Gómez Martín, J. C., and Burrows, J. P.: Spectroscopic studies of the $\mathrm{I}_{2} / \mathrm{O}_{3}$ photochemistry: Part 2. improved spectra of iodine oxides and analysis of the IO absorption spectrum, J. Photoch. Photobio. A, 176, 50-67, 2005.

Thalman, R. and Volkamer, R.: Temperature dependent absorption cross-sections of $\mathrm{O}_{2}-\mathrm{O}_{2}$ collision pairs between 340 and $630 \mathrm{~nm}$ and at atmospherically relevant pressure, Phys. Chem. Chem. Phys., 15, 15371-15381, 2013.

Vandaele, A., Hermans, C., Simon, P., Carleer, M., Colin, R., Fally, S., Merienne, M., Jenouvrier, A., and Coquart, B.: Measurements of the $\mathrm{NO}_{2}$ absorption cross-section from 42000 to $10000 \mathrm{~cm}^{-1}(238-1000 \mathrm{~nm})$ at $220 \mathrm{~K}$ and $294 \mathrm{~K}$, J. Quant. Spectrosc. Ra., 59, 171-184, 1998.
Vasilkov, A. P., Joiner, J., Gleason, J., and Bhartia, P. K.: Ocean raman scattering in satellite backscatter uv measurements, Geophys. Res. Lett., 29, 18-1-18-4, 2002.

Volkamer, R., Spietz, P., Burrows, J. P., and Platt, U.: Highresolution absorption cross-section of glyoxal in the UV/vis and IR spectral ranges, J. Photoch. Photobio. A, 172, 35-46, 2005.

Vountas, M., Rozanov, V. V., and Burrows, J. P.: Impact of rotational Raman scattering on radiative transfer in earth's atmosphere, J. Quant. Spectrosc. Ra., 60, 943-961, 1998.

Vountas, M., Richter, A., Wittrock, F., and Burrows, J. P.: Inelastic scattering in ocean water and its impact on trace gas retrievals from satellite data, Atmos. Chem. Phys., 3, 1365-1375, doi:10.5194/acp-3-1365-2003, 2003.

Wagner, T., Deutschmann, T., and Platt, U.: Determination of aerosol properties from MAX-DOAS observations of the Ring effect, Atmos. Meas. Tech., 2, 495-512, doi:10.5194/amt-2-4952009, 2009.

Wagner, T., Andreae, M. O., Beirle, S., Dörner, S., Mies, K., and Shaiganfar, R.: MAX-DOAS observations of the total atmospheric water vapour column and comparison with independent observations, Atmos. Meas. Tech., 6, 131-149, doi:10.5194/amt6-131-2013, 2013.

Weitkamp, C.: Range-resolved optical remote sensing of the Atmosphere, Springer, NY, USA, 2005. 